\title{
Identification of multiple vasotocin receptor cDNAs in teleost fish: Sequences, phylogenetic analysis, sites of expression, and regulation in the hypothalamus and gill in response to hyperosmotic challenge
}

\author{
Sean C. Lema*
}

\begin{abstract}
A B S T R A C T
Vasopressin and its homolog vasotocin regulate hydromineral balance, stress responses, and social behaviors in vertebrates. In mammals, the functions of vasopressin are mediated via three classes of membrane-bound receptors: V1a-type, V1b-type and V2-type. To date, however, only a single class of vasotocin receptor has been identified in teleost fish. Here, cDNAs encoding three putative vasotocin receptors - two distinct V1a-type receptor paralogs (V1a1 and V1a2) and a previously undescribed V2type receptor (V2) - and a single isotocin receptor were isolated and sequenced from the Amargosa pupfish (Cyprinodon nevadensis amargosae). RT-PCR revealed that mRNAs for these receptors differed in expression patterns with V1a1 mRNAs abundant in the brain, pituitary and testis, V1a2 transcripts at greatest levels in brain, heart and muscle, V2 transcripts most common in the gills, heart and kidney, and isotocin receptor mRNAs abundant in the midbrain, pituitary and gonads. In response to an acute hyperosmotic challenge, pro-vasotocin and V2 mRNA levels in the hypothalamus decreased, while transcripts of V1a1 in the hypothalamus and V1a2 in the gills increased. Partial transcripts for structurally related V2-type, as well as multiple V1a-type, receptors were also identified in other teleosts, suggesting that multiple vasotocin receptors may be present in many Actinopterygii fishes.
\end{abstract}

\section{Introduction}

The neurohypophysial hormone arginine vasopressin (VP) is a well established regulator of osmotic balance, vasoconstriction, and social and affiliative behaviors in mammals. In teleost fish, VP's nonmammalian homolog - arginine vasotocin (VT) - plays similar roles by regulating salt and water balance, cardiovascular function, social behaviors and the physiological response to stressors (reviewed by Balment et al., 2006). In teleosts, VT has been shown to control osmotic balance by acting on the kidney and gills (Balment et al., 1993; Warne et al., 2002). VT induces an antidiuretic effect in the kidney by decreasing glomerular filtration rates resulting in a net increase in water reabsorption and decrease in urine flow (Amer and Brown, 1995), while concurrently acting on the gills to alter $\mathrm{Cl}^{-}$permeability (Guibbolini and Avella, 2003; Avella et al., 1999). Accordingly, teleost VT receptor binding, immunoreactivity and mRNAs have been localized to kidney and gill tissues in several teleost species (Guibbolini et al., 1988; Mahlmann et al., 1994; Guibbolini and Avella, 2003; Warne, 2001; Warne et al., 2005; An et al., 2008a,b). VT receptor binding has also been localized to the nervous system of fish (Moons et al., 1989), where VT acts within the brain to regulate behaviors associated with sociality and reproduction (Goodson and Bass, 2001) and on the pituitary gland to modulate adrenocorticotropic hormone $(A C T H)$ release (Baker et al., 1996).

Receptors for VT/VP - as well as for the structurally related nonapeptides oxytocin, mesotocin and isotocin (IT) - are Gprotein coupled membrane receptors characterized by seven transmembrane helices connected via alternating extracellular and intracellular loops, as is typical of class A G-protein coupled membrane receptors including rhodopsin (Barberis et al., 1998; Darlison and Richter, 1999; Palczewski et al., 2000). In mammals, VP acts through three distinct receptors types: V1a-type, V1b-type and V2-type. The amino acid structures of these three receptor types have been described in several species including rats, mice and humans (e.g., Thibonner et al., 1994; Böselt et al., 2009). In birds, three distinct VT receptors have been also identified; these receptors appear to belong to the V1a-type, V1b-type and, tentatively, the V2-type mammalian VP receptor families (Tan et al., 2000; Cornett et al., 2003; Jurkevich et al., 2005). The functional roles of these avian receptors in osmoregulation, stress responses, and oviposition appear to parallel those of VP/VT receptors identified in other vertebrates (Baeyens and Cornett, 2006). Recently, three VT receptors belonging to the mammalian V1a-type, V1b-type and 
V2-type receptor classes were also identified in the firebelly newt (Cynops pyrrhogaster) (Hasunuma et al., 2007). In Actinopterigian fishes, however, only a single type of VT receptor has been identified to date.

VT receptors have now been isolated and described from several teleost fishes ranging from flatfishes to trout (Mahlmann et al., 1994; Conklin et al., 1999; Warne, 2001; An et al., 2008a). All these receptors constitute a single type of VT receptor that groups within the V1a-type class of mammalian VP receptors, based on the receptors' amino acid structural identities and intracellular signal transduction mechanisms. Mahlmann et al. (1994) first demonstrated that the mammalian V1-type VP receptorspecific antagonist $\left[\mathrm{d}\left(\mathrm{CH}_{2}\right)_{5}, \operatorname{Tyr}(\mathrm{Me})^{2}, \mathrm{Arg}^{8}\right]$ vasopressin inhibited VT-induced membrane currents using the white sucker (Catostomus commersoni) VT receptor expressed in Xenopus laevis oocytes. In a separate study using cultured gill epithelium from European sea bass (Dicentrarchus labrax), VT and the V1-type receptor agonist, $\left[\mathrm{Phe}^{2}, \mathrm{Orn}^{8}\right]$-oxytocin, were found to stimulate $\mathrm{Cl}^{-}$secretion, while a mammalian V2-type receptor agonist failed to have any effect (Guibbolini and Avella, 2003). Likewise, flounder (Platichthys flesus) VT receptor expressed in Xenopus laevis oocytes induced a VT-like inward voltage current following application of the mammalian V1-type agonist $\left[\mathrm{Phe}^{2}, \mathrm{Orn}^{8}\right]$-oxytocin, while the mammalian V2type receptor agonist [deamino ${ }^{1}, \mathrm{Val}^{4}, \mathrm{D}-\mathrm{Arg}^{8}$ ]-vasopressin had no effect (Warne, 2001). This flounder VT receptor was shown to act via a phospholipase C (PLC) and inosotol-1,4,5-triphosphate ( $\left.\mathrm{IP}_{3}\right)$ intracellular signaling pathway (Warne, 2001), which is characteristic of the transduction pathways used by mammalian V1-type receptors, but distinct from the adenylate cyclase and cAMP intracellular signaling pathways used by mammalian V2-type receptors (Wargent et al., 1999).

While these studies suggest that the teleost VT receptor acts through a $\mathrm{PLC} / \mathrm{IP}_{3}$ intracellular signaling pathway similar to mammalian V1a-type receptors, there is also biochemical evidence that teleost fish may possess a V2-type receptor, or at least a VT receptor that acts by altering intracellular cAMP levels. In isolated renal tubules from rainbow trout, Perrott et al. (1993) found that VT causes a dose-dependent induction of intracellular cAMP production, a result consistent with the V2-type transduction pathway for VP in mammals (Wargent et al., 1999). Similarly, in trout hepatocytes and gill membranes, VT has been shown to alter adenylate cyclase activity and inhibit cAMP accumulation induced by glucagon (Guibbolini and Lahlou, 1987; Guibbolini et al., 2000). This inhibition appears to occur via VT induction of an inhibitory G-protein pathway (Guibbolini and Lahlou, 1992). Taken together, these studies suggest that some teleosts may possess a VT receptor that acts by altering cAMP intra-cellular signaling.

Recently, two VT receptors, one mammalian V1a-type and one mammalian V2-type, were also identified in a Sarcopterygian fish, the African lungfish (Protopterus annectens) (Konno et al., 2009). This lungfish V2 receptor acts by modulating intracellular cAMP concentrations via a transduction pathway homologous to that of mammalian V2-type receptors, and consistent with the biochemical evidence for a V2-type receptor in teleosts (Guibbolini and Lahlou, 1987, 1990). If lungfish possess VT receptors from both the V1a-type and V2-type families, then when did the multiple nonapeptide hormone receptors presently seen in tetrapods first evolve? Did a single VT/VP receptor evolve into the distinct V1atype, V1b-type and V2-type receptors prior to the divergence of the modern day tetrapod lineage from fish?

Here, cDNAs for VT and IT receptors were isolated and sequenced from the brain of the teleost Amargosa River pupfish, Cyprinodon nevadensis amargosae. The VT system has been studied previously in this species for its role in the regulation, and subsequent evolutionary diversification, of aggression and other behaviors in allopatric populations inhabiting the Death Valley region of California and Nevada, USA. VT modulates aggression in male Amargosa pupfish (Lema and Nevitt, 2004a), and in previous work, Lema and Nevitt (2004b) discovered that wild allopatric populations of this species differ in the size of hypothalamic VTimmunoreactive neurons. This population-level variation in neural VT expression results from the interacting effects of variation in habitat conditions (e.g., salinity, temperature) and an evolved genetic difference between populations in how the VT system responses to environmental conditions (Lema, 2006).

In the current study, cDNAs encoding putative receptors for VT and IT were isolated and sequenced from $C$. n. amargosae, as a first step toward exploring how receptor regulation at the level of target tissues may contribute to evolutionary divergence in VT-mediated social behaviors, as has been seen in mammalian systems (e.g., Insel et al., 1994). Using degenerate primer PCR, three putative VT receptor cDNAs, and one IT receptor CDNA, were identified. Two of these VT receptor cDNAs appear to be paralogs that show greatest homology to mammalian V1a-type receptors, while the third cDNA encodes a previously undescribed teleost VT receptor with closest homology to mammalian V2-type receptors.

\section{Materials and methods}

\section{1. cDNA cloning of vasotocin and isotocin receptors}

\subsubsection{Total RNA isolation}

Amargosa River pupfish (Cyprinodon nevadensis amargosae) adults were collected from the Amargosa River near Dumont Dunes, San Bernardino County, California, USA, on 29 May, 2007 (salinity, $1.3 \mathrm{ppt}$; temperature, $22.2^{\circ} \mathrm{C}$ ). An adult male pupfish (body mass, $1.81 \mathrm{~g}$; standard length, $40.05 \mathrm{~mm}$ ) was euthanized in tricaine methanesulfonate (MS222; Argent Chemical, Redmond, WA), and the whole brain with connected pituitary dissected and stored in RNAlater (Applied Biosystems, Inc., Foster City, CA). Total RNA was extracted using Tri-Reagent RT (Molecular Research Center, Cincinnati, $\mathrm{OH}$ ) with bromoaniosole as the phase separation reagent. The resulting total RNA was DNase I treated (Invitrogen, Carlsbad, CA) and then quantified (260:280 ratio of 2.02; NanoDrop Technologies, Wilmington, DE). RNA quality was confirmed by electrophoresis on a $1 \%$ agarose gel stained with ethidium bromide.

\subsubsection{Determination of partial VT and IT receptor $c D N A$ sequences}

To obtain partial cDNA sequences, first strand cDNA was synthesized in a $20 \mu \mathrm{l}$ reverse transcription reaction by incubating $2 \mu \mathrm{g}$ of total RNA template $(4.83 \mu \mathrm{l})$ with $1.0 \mu \mathrm{l}$ annealing buffer, $1.0 \mu \mathrm{l}$ of random primers, and $1.17 \mu \mathrm{l}$ of RNase-free $\mathrm{H}_{2} \mathrm{O}$ (Sigma, St. Louis, MO) at $65^{\circ} \mathrm{C}$ for $5 \mathrm{~min}$. Subsequently, $10 \mu \mathrm{l}$ of $5 \times$ buffer and $2 \mu \mathrm{l}$ of Superscript III Reverse Transcriptase Enzyme Supermix (Invitrogen) were added, and the mixture was incubated at $25^{\circ} \mathrm{C}$ for $10 \mathrm{~min}$ followed by $50^{\circ} \mathrm{C}$ for $50 \mathrm{~min}$ and $85^{\circ} \mathrm{C}$ for $5 \mathrm{~min}$.

PCR was performed using degenerate primers designed from consensus regions of cDNA sequences for VT and IT receptors from fish and amphibians. For the V1type teleost VT receptor, one set of nested degenerate primers was designed to VT receptor cDNAs described previously from European flounder (Platichthys flesus, GenBank accession no. AF184966) (Warne, 2001) and cichlid (Astatotilapia burtoni, accession no. AF517936). For the V2-type VT receptor, BLASTX searches of GenBank using cDNA sequences for the V2 receptor from the amphibians Taricha granulosa (EF567078) and Cynops pyrrhogaster (AB274038) identified two putative teleost V2 receptor sequences. These two sequences - an EST sequence (GenBank no. XM_001345969) from zebrafish (Danio rerio) and a genomic DNA sequence (GenBank no. CAAE01014991) comprising part of chromosome 9 of puffer (Takifugu rubripes) - were aligned (Sequencher, v.4.8, Gene Codes Corp., Ann Arbor, MI) and the resulting alignment used to design nested degenerate primers. For the isotocin receptor, nested primers were designed to the IT receptor cDNA sequence from white sucker (Catostomus commersonii, accession no. X87783) (Hausmann et al., 1995) and deduced sequence from zebrafish genomic DNA (XM_001341471). Degenerate primers for all receptors are provided in Table 1.

Partial cDNAs for $\beta$-actin and elongation factor- $1 \alpha(E F-1 \alpha)$ were also isolated and sequenced from Amargosa River pupfish for use as control genes (Table 1). Degenerate primers for $\beta$-actin were designed from zebrafish (AF057040), mud carp (Cirrhinus molitorella; DQ007446), goldfish (Carassius auratus; AB039726) and the carp Spinibarbus denticulatus (DQ656598), and to the $\beta$-actin gene sequence from Rivulus marmoratus (AF168615). For $E F-1 \alpha$, degenerate nested primers were designed to consenus regions of EF-1 $\alpha$ cDNAs from Oryzias latipes (NM_001104662), Pagrus major (AY190693), Carassius auratus (AB056104) and Seriola quinqueradiata (AB032900). These primer sets amplified a 697-bp partial sequence of $\beta$-actin (EU886377) and a 827-bp partial sequence of EF-1 $\alpha$ from Amargosa pupfish (EU906930). 
Table 1

Degenerate primers used for isolation of partial cDNAs for VT/IT receptors, $\beta$-actin and EF- $1 \alpha$.

\begin{tabular}{|c|c|c|c|}
\hline Receptor & Primer name & Direction & Sequence $\left(5^{\prime}\right.$ to $\left.3^{\prime}\right)$ \\
\hline V1-type & $\begin{array}{l}\text { V1-F1 } \\
\text { V1-R1 } \\
\text { V1-N1 } \\
\text { V1-N2 }\end{array}$ & $\begin{array}{l}\text { Sense } \\
\text { Antisense } \\
\text { Sense } \\
\text { Antisense }\end{array}$ & $\begin{array}{l}\text { CACAGAGGGGCAGTGCCAT } \\
\text { CTCGCTCAGGGAGAAGATGAA } \\
\text { GTGGT(C/T)GC(C/T)TTCTTCCAGGT } \\
\text { CGGT(G/T)ATCCAGGTGAT(A/G)TACG }\end{array}$ \\
\hline V2-type & $\begin{array}{l}\text { V2-F1 } \\
\text { V2-R1 } \\
\text { V2-N1 } \\
\text { V2-N2 }\end{array}$ & $\begin{array}{l}\text { Sense } \\
\text { Antisense } \\
\text { Sense } \\
\text { Antisense }\end{array}$ & $\begin{array}{l}\text { ATGGTCAA(C/T)CTGTGTGTTGC(A/C)GA } \\
\text { ACCTGACA(A/G/T)A(C/T)(A/G)GTGAT(A/G)AT(A/G)A(A/T)G } \\
\text { GTTTGC(A/C/T)TCCTC(C/T)TACATGATTGT } \\
\text { GTCATCCAGGT(A/G)AC(A/G)TAGGC }\end{array}$ \\
\hline ITR & $\begin{array}{l}\text { ITR-F1 } \\
\text { ITR-R1 } \\
\text { ITR-N1 } \\
\text { ITR-N2 }\end{array}$ & $\begin{array}{l}\text { Sense } \\
\text { Antisense } \\
\text { Sense } \\
\text { Antisense }\end{array}$ & $\begin{array}{l}\text { ATGAAGCACCTCAGCATTGC } \\
\text { AACATGGAGATGATAAAGGGCAT } \\
\text { CCTCAACTCATTTGGGACATCA } \\
\text { GTCATTTTAACGGTGGTGATTTTGG }\end{array}$ \\
\hline$\beta$-actin & $\begin{array}{l}\beta \text {-actin-F1 } \\
\beta \text {-actin-R1 } \\
\beta \text {-actin-N1 } \\
\beta \text {-actin-N2 }\end{array}$ & $\begin{array}{l}\text { Sense } \\
\text { Antisense } \\
\text { Sense } \\
\text { Antisense }\end{array}$ & $\begin{array}{l}\text { ATCATGTT(C/T)GAGACCTTCAACACCC } \\
\text { TACTCCTGCTTGCT(A/G)ATCCACAT } \\
\text { GTGACATCAAGGAGAAGCT(G/C)TGCTA } \\
\text { GCAATGCC(A/G)GGGTACATGGT }\end{array}$ \\
\hline$E F-1 \alpha$ & $\begin{array}{l}\text { EF1a-F1 } \\
\text { EF1a-R1 } \\
\text { EF1a-N1 } \\
\text { EF1a-N2 }\end{array}$ & $\begin{array}{l}\text { Sense } \\
\text { Antisense } \\
\text { Sense } \\
\text { Antisense }\end{array}$ & $\begin{array}{l}\text { GGGAAAGGAAAA(A/G)A(C/T)CCACAT } \\
\text { C(C/T)TTGAC(A/G)GACACGTTCTT(G/C)A } \\
\text { CACAT(C/T)AACATCGTGGT(C/T)ATTGGC } \\
\text { ACGTTGTCACCAGG(A/C/G)(A/G)(C/T)(A/G)GC }\end{array}$ \\
\hline
\end{tabular}

For each gene of interest, first-strand cDNA was amplified in a $50 \mu \mathrm{l}$ PCR reaction containing $2 \mu \mathrm{l}$ of reverse-transcribed cDNA, $3.0 \mu \mathrm{l} \mathrm{MgCl} 2(25 \mathrm{mM}), 10 \mu \mathrm{l}$ of $10 \times$ Flexi buffer, $1.0 \mu \mathrm{l}$ dNTP, $0.25 \mu \mathrm{l}$ GoTaq polymerase (Promega, Madison, WI), and $31.75 \mu \mathrm{l}$ RNase-free $\mathrm{H}_{2} \mathrm{O}$ under a thermal profile of $95^{\circ} \mathrm{C}$ for $2 \mathrm{~min}$ followed by 35 cycles of $95^{\circ} \mathrm{C}$ for $30 \mathrm{~s}, 50-52^{\circ} \mathrm{C}$ for $30 \mathrm{~s}$, and $72{ }^{\circ} \mathrm{C}$ for $1 \mathrm{~min}$, and ending with $72{ }^{\circ} \mathrm{C}$ for $10 \mathrm{~min}$ on a PT-100 Thermal Cycler (MJ Research). When electrophoresis of the PCR product on a $1.2 \%$ agarose gel revealed a band of predicted size, the cDNA was purified (QIAquick PCR Purification Kit, Qiagen, Inc., Valencia, CA) and sequenced on a ABI Prism 3100 Genetic Analyzer (Applied Biosystems, Inc.) using ABI Big Dye Terminator Cycle Sequencing Kit 3.1. Consensus sequences for each partial length cDNA were assembled using Sequencher ${ }^{\mathrm{TM}}$ v.4.8 (Gene Codes Corp., Ann Arbor, MI).

\subsubsection{Cloning and sequencing of full-length cDNAs}

Nested gene-specific primers for all identified VT and IT receptors from Amargosa River pupfish were designed from the partial cDNA sequences obtained above. These primers were then used to acquire the full-length cDNA sequences by $5^{\prime}-$ and 3'-rapid amplification of cDNA ends (BD SMART RACE cDNA Amplification Kit, Clontech Laboratories, Inc., Mountain View, CA). Gene-specific primers for the RACE reactions are provided as part of the accompanying on-line Supplemental Materials, Table 1. First-strand cDNA was amplified in $50 \mu \mathrm{l}$ reactions with the following reaction components: $5 \mu \mathrm{l}$ of $10 \times$ High Fidelity PCR Buffer, $2 \mu \mathrm{l}$ of $\mathrm{MgSO}_{4}(50 \mathrm{mM}), 1 \mu \mathrm{l}$ of dNTPs $(10 \mathrm{mM})$, and $0.2 \mu \mathrm{l}$ of Platinum Taq High Fidelity Polymerase (Invitrogen, Inc.), along with $3 \mu \mathrm{I}$ of cDNA template. Amplification occurred under a thermal profile of 5 cycles of $94^{\circ} \mathrm{C}$ for 30 s followed by $72^{\circ} \mathrm{C}$ for 2 min; 5 cycles of $94^{\circ} \mathrm{C}$ for $30 \mathrm{~s}, 70^{\circ} \mathrm{C}$ for $30 \mathrm{~s}$, and $72^{\circ} \mathrm{C}$ for $2 \mathrm{~min}$, and then 25 cycles of $94^{\circ} \mathrm{C}$ for $30 \mathrm{~s}, 68^{\circ} \mathrm{C}$ for $30 \mathrm{~s}$, and $72^{\circ} \mathrm{C}$ for $2 \mathrm{~min}$. Electrophoresis of the $5^{\prime}$ - and $3^{\prime}$-RACE products on $1.2 \%$ agarose gels revealed single bands for some receptors; if a single band was not evident after the initial PCR, the nested gene-specific primers were used to amplify the $5^{\prime}$ - and $3^{\prime}$-RACE products. The resulting cDNAs were cloned (TOPO TA Cloning Kit, Invitrogen) using ampicillin resistant bacteria, and the resulting plasmids were extracted, purified (Purelink ${ }^{\mathrm{TM}}$ Quick Plasmid Miniprep Kit, Invitrogen) and sequenced. Full-length cDNA sequences were obtained by aligning overlapping $5^{\prime}$ - and $3^{\prime}$-RACE products (Sequencher ${ }^{\mathrm{TM}}$ v.4.8 software) and compared against other neurohypophyseal receptor sequences using BLAST.

The full-length sequence for each CDNA was confirmed by PCR using primers designed to the $5^{\prime}$ and $3^{\prime}$ untranslated regions (UTRs) of each transcript. Primers used in these full-length PCRs are provided as on-line Supplemental Material, Table 2. Reverse-transcribed total RNA was amplified in $50 \mu \mathrm{l}$ reactions containing $2 \mu \mathrm{l}$ of cDNA template, $21 \mu \mathrm{l}$ nuclease-free $\mathrm{H}_{2} \mathrm{O}, 25 \mu \mathrm{l}$ of Taq DNA polymerase (GoTaq Colorless Master Mix, Promega), and $1 \mu \mathrm{l}$ each of forward and reverse primer under a profile of $95^{\circ} \mathrm{C}$ for 2 min followed by 35 cycles of $95^{\circ} \mathrm{C}$ for $30 \mathrm{~s}, 56^{\circ} \mathrm{C}$ for $30 \mathrm{~s}$, and $72{ }^{\circ} \mathrm{C}$ for $4 \mathrm{~min}$, and then $72^{\circ} \mathrm{C}$ for 5 min. The resulting PCR products were examined on $\mathbf{0 . 8 \%}$ agarose gels, and then purified (QIAquick PCR Purification Kit, Qiagen, Inc.) and sequenced.

Amino acid alignments between the resulting pupfish VT/IT receptors and homologous receptors for vertebrate neurohypophyseal hormones were made using the ClustalW method (Lasergene software; DNASTAR, Inc., Madison, WI). The secondary structure of each membrane receptor was predicted using the Predict Transmembrane Topology (MEMSTAT v.3) program on the PSIPRED Protein Structure Prediction Server (http://bioinf.cs.ucl.ac.uk/psipred/) (Jones et al., 1994; Jones,

Table 2

Nucleotide sequences for primers and Taqman probes used in quantitative real-time RT-PCR.

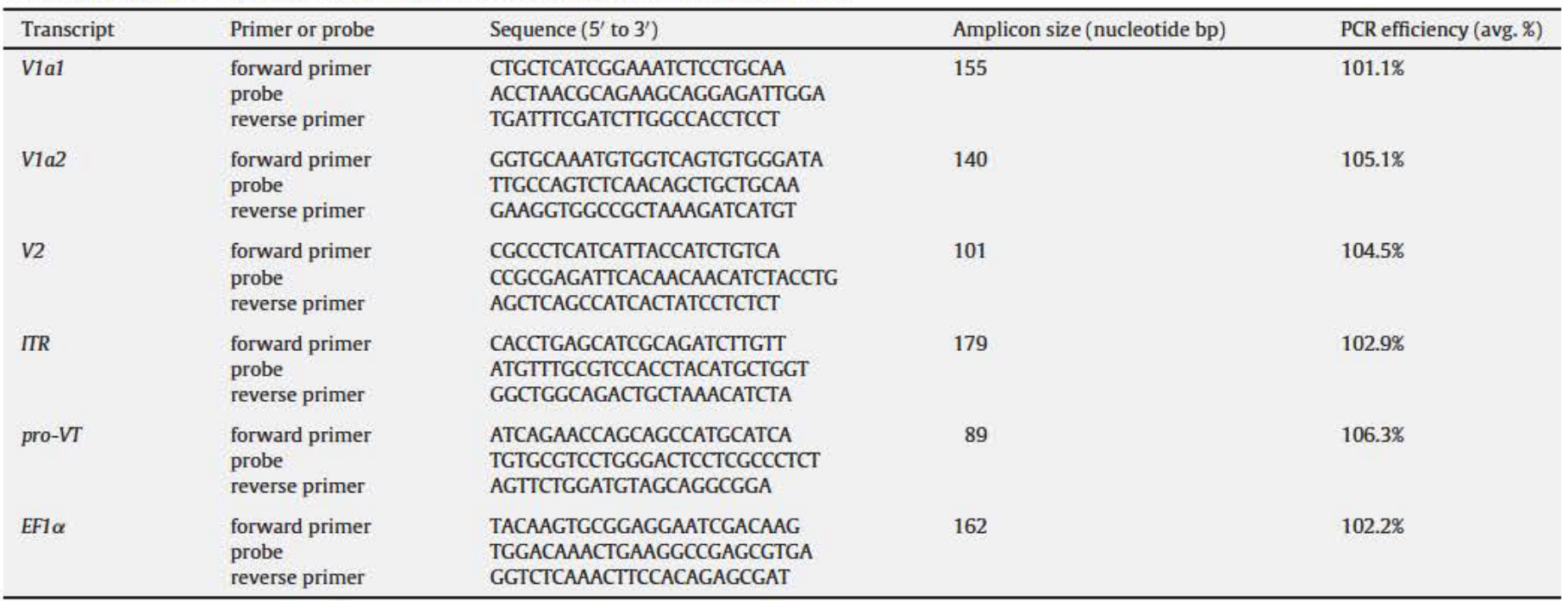


Table 3

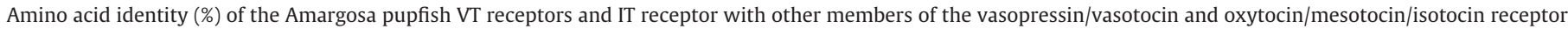
family.

\begin{tabular}{|c|c|c|c|c|c|}
\hline & Accession no. & V1a1 pupfish & V1a2 pupfish & V2 pupfish & ITR pupfish \\
\hline V1a1 pupfish & GQ981412 & - & 69.74 & 32.99 & 50.50 \\
\hline V1a2 pupfish & GQ981413 & 69.74 & - & 34.07 & 47.81 \\
\hline V2 pupfish & GQ981414 & 32.99 & 34.07 & - & 33.76 \\
\hline ITR pupfish & GQ981415 & 50.50 & 47.81 & 33.76 & - \\
\hline VTR flounder & AF184966 & 70.69 & 85.16 & 33.48 & 49.48 \\
\hline VTR cichlid & AF517936 & 70.59 & 84.11 & 31.72 & 48.83 \\
\hline VTR white sucker & X76321 & 70.95 & 73.25 & 33.26 & 51.02 \\
\hline V1a lungfish & AB377531 & 64.11 & 68.57 & 33.97 & 49.75 \\
\hline V1/V1a firebelly newt & AB274037 & 58.94 & 64.16 & 32.92 & 48.77 \\
\hline V1a chicken & NMOO 1110438 & 59.33 & 62.79 & 33.20 & 45.07 \\
\hline V1a mouse & NM_016847 & 54.59 & 58.69 & 33.00 & 44.53 \\
\hline V1a human & NM000706 & 53.81 & 58.31 & 32.79 & 45.68 \\
\hline V3/V1b firebelly newt & AB284503 & 49.88 & 52.32 & 33.61 & 44.17 \\
\hline V1b chicken & NMOO 1031498 & 49.88 & 46.90 & 36.34 & 46.76 \\
\hline V1b mouse & NM_011924 & 50.49 & 51.25 & 35.55 & 47.25 \\
\hline V1b human & NM000707 & 49.64 & 50.37 & 36.70 & 47.19 \\
\hline V2 lungfish & AB377532 & 42.08 & 41.96 & 47.46 & 41.07 \\
\hline V2 firebelly newt & AB274038 & 41.32 & 44.48 & 44.35 & 39.89 \\
\hline V2 chicken & NMOO 1031479 & 44.59 & 44.39 & 35.81 & 44.00 \\
\hline V2 mouse & NM_019404 & 39.53 & 39.40 & 41.54 & 38.22 \\
\hline V2 human & NM000054 & 39.22 & 38.59 & 41.58 & 36.41 \\
\hline ITR white sucker & X87783 & 48.39 & 50.26 & 33.12 & 73.15 \\
\hline MTR roughskinned newt & DQ186599 & 46.80 & 49.47 & 33.83 & 62.69 \\
\hline
\end{tabular}

Abbreviations: VTR, vasotocin receptor; V1a, vasopressin/vasotocin V1a receptor; V1b, vasopressin/vasotocin V1b receptor; V3/V1b, vasotocin V3/V1b receptor; V2, vasopressin/vasotocin V2 receptor; ITR, isotocin receptor; MTR, mesotocin receptor.

2007), and hydrophobicity plots for each deduced receptor amino acid sequence were generated on the Kyte-Doolittle scale (Kyte and Doolittle, 1982).

\subsection{Sequencing of VT and IT receptor genes from genomic DNA}

Genomic DNA was isolated from the liver using the DNeasy Cell and Tissue Kit (Qiagen) prior to being treated with RNase (Promega). Genomic DNA was amplified in a $50 \mu \mathrm{l}$ PCR reaction containing $2 \mu \mathrm{l}$ of DNA template ( $200 \mathrm{ng}), 25 \mu \mathrm{l} \mathrm{GoTaq} \mathrm{Col-}$ orless Master Mix (Promega), $21 \mu \mathrm{l}$ nuclease-free $\mathrm{H}_{2} \mathrm{O}$, and $1 \mu \mathrm{l}$ each of forward and reverse primer $(10 \mu \mathrm{M})$ using a thermal profile of 1 cycle of $95^{\circ} \mathrm{C}$ for $10 \mathrm{~min}, 40$ cycles of $95^{\circ} \mathrm{C}$ for $1 \mathrm{~min}, 54^{\circ} \mathrm{C}$ for $1 \mathrm{~min}$, and $72^{\circ} \mathrm{C}$ for $3-4 \mathrm{~min}$, followed by a final extension of $72^{\circ} \mathrm{C}$ for $10 \mathrm{~min}$. Primer pairs were identical to those used above for full-length cDNA sequence confirmation, and are provided as on-line Supplemental Material (Table 2). The resulting PCR products were visualized on $0.8 \%$ agarose gels with ethidium bromide (Invitrogen, Inc.) and then purified (QIAQuick PCR Purification Kit, Qiagen, Inc.) and sequenced.

\subsection{Phylogeny construction}

Full length amino acid sequences for all identified pupfish VT and IT receptors were aligned to the sequences of receptors in the VP/VT, OT/MT/IT, and related neuropeptide families from other vertebrates and invertebrates obtained from GenBank. Amino acid sequences were aligned using ClustalX (Larkin et al., 2007). Phylogenetic analyses were conducted using MEGA v.4.1beta (Tamura et al., 2007), and a tree was assembled by the Neighbor-Joining method (Saitou and Nei, 1987) using a p-distance model. All positions containing alignment gaps were eliminated only in pairwise sequence comparisons (pairwise deletion of gaps). Confidence values for clusters of associated taxa were obtained by bootstrap tests (1000 replicates).

\subsection{Tissue distribution patterns of VT and IT receptors}

One adult male (body mass, $2.22 \mathrm{~g}$; SL, $41.50 \mathrm{~mm}$ ) and one adult female ( $1.65 \mathrm{~g}$, $37.40 \mathrm{~mm}$ ) pupfish were collected by minnow trap on 28 May, 2007 from the Amargosa River. Pupfish were immediately euthanized in MS222, and the brain, pituitary gland, gills, heart, gonads, liver, kidney, gastrointestinal (GI) tract and a piece of skeletal muscle from the side of the caudal peduncle were dissected. The dissected brain was further subdivided into the forebrain (olfactory bulb and telencephalon), midbrain (optic tectum and hypothalamus), cerebellum, and hindbrain (medulla oblongata). All tissues were stored individually in RNAlater (Applied Biosystems, Inc.). Total RNA was extracted from each tissue using Tri-Reagent (Molecular Research Center, Inc.) and treated with DNase I (Invitrogen) before being quantified by spectrophotometry. First strand cDNA was then synthesized in $15 \mu \mathrm{l}$ reverse transcription reactions containing $0.72 \mu \mathrm{g}$ of total RNA template and the RT reaction conditions described above. PCR was performed using GoTaq MasterMix (Promega) under the following thermal profile: $95^{\circ} \mathrm{C}$ for 2 min, $30-34$ cycles of $95^{\circ} \mathrm{C}$ for $30 \mathrm{~s}, 55^{\circ} \mathrm{C}$ for $30 \mathrm{~s}$, and $72^{\circ} \mathrm{C}$ for $1 \mathrm{~min}$, followed by $72^{\circ} \mathrm{C}$ for $5 \mathrm{~min}$ (except for $\beta$-actin, where PCR was performed for only 24 cycles). Primers for each transcript are provided in the on-line Supplementary Materials, Table 3. PCR products (range:
224-291 bp nucleotides in size) were visualized on $2 \%$ agarose gels with ethidium bromide (Invitrogen Corp, Carlsbad, CA) and photographed using a BioRad Gel Doc 2000 Gel Documentation System (BioRad Laboratories, Hercules, CA).

\subsection{Semiquantitative RT-PCR evaluation of gonadal VT/IT receptor mRNA} abundance

A total of four $(n=4)$ sexually mature female (body mass, $1.42 \pm 0.18 \mathrm{~g}$; SL, $37.12 \pm 1.88 \mathrm{~mm}$; mean \pm SEM) and four $(n=4)$ sexually mature male (body mass, $1.69 \pm 0.15 \mathrm{~g} ; \mathrm{SL}, 37.37 \pm 1.18 \mathrm{~mm}$ ) pupfish were collected by minnow trap from the Amargosa River on 29 May 2009. Fish were quickly euthanized in MS222, and the testes and ovaries were dissected and stored in RNAlater. Microscopic examination of one gonad from each fish indicated that all fish were sexually mature, and the presence of mature oocytes throughout the ovaries suggested that it is likely that these large pupfish were actively spawning, as would be expected for this population during April-May (Soltz, 1974). Total RNA was extracted from the other gonad of each fish (Tri-Reagent; Molecular Research Center, Inc.), DNase I (Invitrogen) treated, and quantified by spectrophotometry before first strand cDNA for each sample was synthesized in $25 \mu \mathrm{l}$ reverse transcription reactions containing $1.5 \mu \mathrm{g}$ of total RNA template under the RT reaction conditions described above. PCR was performed using GoTaq MasterMix (Promega) under the following thermal profile: $95^{\circ} \mathrm{C}$ for $2 \mathrm{~min}, 24-35$ cycles of $95^{\circ} \mathrm{C}$ for $30 \mathrm{~s}, 55^{\circ} \mathrm{C}$ for $30 \mathrm{~s}$, and $72^{\circ} \mathrm{C}$ for $1 \mathrm{~min}$, followed by $72^{\circ} \mathrm{C}$ for $5 \mathrm{~min}$. Primers for each receptor were identical to those described above for assessing tissue distribution patterns of each receptor transcript. PCR products were visualized on $2 \%$ agarose gels with ethidium bromide (Invitrogen) and photographed using a BioRad Gel Doc 2000 Gel Documentation System (BioRad Laboratories, Hercules, CA). Relative PCR product band intensity was then quantified in each testis and ovary using Image $1.37 \mathrm{v}$ software (National Institutes of Health, USA). Statistical comparisons of gonadal transcript abundance for each VT receptor are expressed as relative levels, so that the tissue (testis or ovary) with the lower mean value obtained a relative value of 1 . Statistical comparisons were then calculated between the sexes using $t$ tests (Zar, 1996).

\subsection{Salinity regulation of pro-VT and VT/IT receptor $m R N A s$}

\subsubsection{Acute salinity challenge}

Juvenile Amargosa pupfish (body mass, $0.55 \pm 0.08 \mathrm{~g}$; standard length, $24.70 \pm 0.78 \mathrm{~mm}$; mean $\pm \mathrm{SEM}$ ) were collected from the Amargosa River on 30 May 2009 using minnow traps. Physical parameters in the Amargosa River were recorded as a salinity of $2.1 \mathrm{ppt}$, conductivity of $4060 \mu \mathrm{S}$, and dissolved oxygen content of $9.57 \mathrm{mg} / \mathrm{l}$ (YSI 85, YSI Inc., Yellow Springs, OH). Pupfish were maintained in 19l, aerated tanks at ambient river temperatures for 7 days before being haphazardly assigned to one of three salinity treatments: $2.1 \mathrm{ppt}$ (control), $17 \mathrm{ppt}$, or $34 \mathrm{ppt}$. Salinity changes in the aerated tanks were generated by the gradual addition of hyper-saline water ( $50 \mathrm{ppt}$; made from ambient water from the Amargosa River with Instant Ocean ${ }^{\circledR}$, Aquarium Systems, Sarrebourge, France) over a period of $2 \mathrm{~h}$ until experimental salinities ( 17 ppt or $34 \mathrm{ppt}$ ) were achieved. Fish were maintained in these treatment groups for periods of either $5 \mathrm{~h}$ or $20 \mathrm{~h}$ (after beginning salinity 
elevation), at which time fish were collected, euthanized in MS222, and the hypothalamus and gills were dissected and stored in RNAlater (Ambion) at $4{ }^{\circ} \mathrm{C}$ overnight, prior to storage at $-20^{\circ} \mathrm{C}$ until RNA extraction.

\subsubsection{Quantitative real-time RT-PCR assays}

Total RNA was extracted from the hypothalamus and gills (Tri-Reagent; Molecular Research Center) and DNase I (Invitrogen) treated. Total RNA for each sample was diluted to a concentration of $15 \mathrm{ng} / \mu \mathrm{l}$ before being reverse-transcribed (RT) in $20 \mu \mathrm{l}$ reactions containing $4.0 \mu \mathrm{l} 5 \times$ buffer and $2.0 \mu \mathrm{l}$ DTT $(0.1 \mathrm{M}$; Invitrogen, Carlsbad, CA), $1.0 \mu \mathrm{ldNTP}(10 \mathrm{mM}$ ) and $0.34 \mu \mathrm{l}$ random hexamer (Promega), $0.20 \mu \mathrm{l}$

(A) .227 actagatgcagggagctgatcagtggcgcagggcgctgtacagcagacggatccacagctgcgttttgcgccacagatg -147 gaacattgctttgtttgaacctcaccaattctctcctgttggtcctgagctgagcaccogggaggctgacagcctggctgtc .64 cgcgggtcacggttacgcactggcgggttggcacccgtgcacccgagggaaagaggctgccact

+1 ATGCTCTGCTCATCGGAAATCTCCTGCAACATCACAGAAGTCTTCAACCTAACGCAGAAGCAG M L C C S S S E I S S C N N I T E V F N L T +64 GAGATTGGAGCGGCGGGGTCTGCTCGGAACCTCAGCGGGAAAACGAACGACACCGACCCGTTC

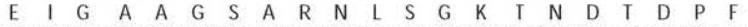
+127 GGGCGCAACGAGGAGGTGGCCAAGATCGAAATCACGGTCCTGAGCCTGGCTTTCGTGGCGGCG $\begin{array}{lllllllllllllllllllll}G & R & N & E & E & V & A & K & \text { I } & E & \text { I } & T & V & L & S & L & A & F & V & A & A\end{array}$ +190 GTGGTGGGGAACCTGAGCGTCCTGCTGGCCATGTACAGGAGCCGCAGGAAGCTGTCTCGGATC

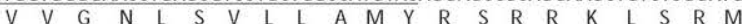
+253 CACCTGTTCATGAAGCACCTGAGCCTGGCGGACCTGGTGGTCGCCTTCT CCAGGTTCTGCCG +316 CAGCTCTGCTGGGAGGTCACCTTCCGCTTCTACGGGCCGGACTTTCTGIGCCGCATCGTGAAG

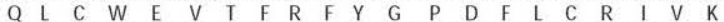
*379 CACCTGCAGGTTCTGGGCATGTTCGCTTCCACCTACATGATGGTGATGATGACGCTGGACCGC +442 TACATCGCCATCTGCCACCCGCTGCAGACCCTCCAGCAGCCCACGCGGCGCGCCTACATCATG $\begin{array}{llllllllllllllllllllll}Y & I & A & I & C & H & P & L & Q & T & L & Q & Q & P & T & R & R & A & Y & I & M\end{array}$ +505 ATAAGCTCCACCTGGGCGTGCAGCCTGGTCCTCAGCACCCCGCAGTACTGCATCTTCTCCC +568 AGCGAGGTGCGGCCCGGATCGGCCGTCTACGACTGCTGGGGGCACTTCGTGGAGCCGTGGGGG

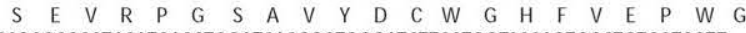
+631 CCGCGCGCCTACATCACCTGGATCACGGCTGGGATCTTCCTGGTCCCCGTGGCTGTGCTCGTT

$\begin{array}{lllllllllllllllllllll}P & R & A & Y & I & T & W & I & T & A & G & I & F & L & V & P & V & A & V & L & V\end{array}$ +697 ITCTGCTACGGGTTCATCTGCAGGGCGATCTGGAGGAATCTGAAGTGCAAAACCCGCAGGAAG

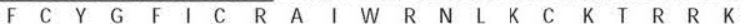
+757 AGCGCGGACGCGGTGGTGGAGGCCACCAAGAGCGGGATCCTGGGCAGGAGCTCTGTGAGCAGC $\begin{array}{lllllllllllllllllllll}S & A & D & A & V & V & E & A & T & K & S & G & \text { I } & \text { L } & G & R & S & S & V & S & S\end{array}$ +820 GTCTCCACCATCTCCCGCGCAAAATTACGCACGGTCAAGATGACTTITGTGATCGTGGTGGCC

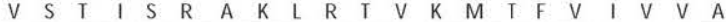
+883 TACGTGGTGTGCTGGGCTCCGTTCTTCACCGTGCAGATGTGGTCCGTGTGGGACAAGACCTTC

-946 TCCTGGGAgtaggactttttggccttctgacgtgttgctaccggcgttgcggaagcaggacacgcgggccagcgcgc S W D

aataacacgcttacgtaatacgatccgtcggggaacggcctacgcataccagtccgacaccctgctgtctgcgggacaacc gccgtgcacccggggtccgcggtccaggttcgcgagcccgctcgcgaggccgcttcacgcttacaccatcaaaaactttga ccacaagccaccccgcaagaaaccggcctgtgttagggtggtgatacagttgatgctgttggtcttaccccatggcagaaaa gtattccgtgtgttaggcttaaagcagttattaaattaaaaaaagcctgaatatgaccacctgaaaggatcattttgatttta tgctcattttaaagaccatgactctttatttacttggaaaattagaatttaaggacaacag

+960 TGATTCTGAGAACACAGCAGTGTCTCTGTCTGCGCTGCTGGCGAGTCTGAACAGTTGCTGCAAC D S E N I A V S L S A L L A S L N S C C N 1016 CCGTGGATATACATGACCTITAGCGGCCACCTTCTCCAGGATTTCATGCACTGCTTCTCCTGT

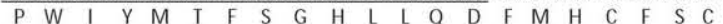

+1087 TGCTACCGGCTGCGGGACAAGTTGAAAAACAGGACTCGGACAGCAGCATCCGTCGGACCACC $\begin{array}{lllllllllllllllllllll}C & Y & R & L & R & D & K & L & K & K & Q & D & S & D & S & S & \text { I } & R & R & T & T\end{array}$ +1150 CTGCTGTCCCGCCTGCAGGGTCCGCGTCTGTCAAAGCCCTTCAGAGAACTCAACTACACCATC

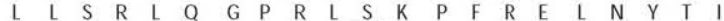
+1213 AAAAACTGTCCACAAGCCACGCCTGCATCATGAccctcaataaaccggcctgttaggggaattaacgcccggg $\begin{array}{llllllllllll}K & N & C & P & Q & A & T & P & A & S & \text { stop }\end{array}$

+1286 atgctgggtttgttgcagtctaaacggggagcgtttaccccatggcacaaaaagtattcatcgcactataattgaggcttaaa +1370 aaacagcagtttaatttaacatttaaaaaaaaaactcttttaatg

(B)

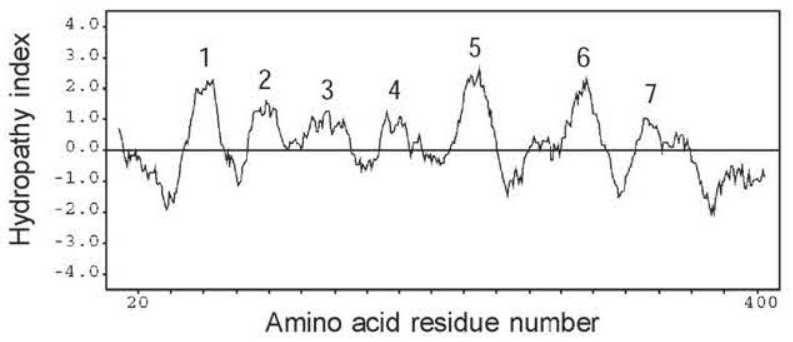

RNaseOUT inhibitor ( $40 \mathrm{U} / \mu \mathrm{l}$, Invitogen), $0.25 \mu \mathrm{l}$ Superscript III reverse transcriptase

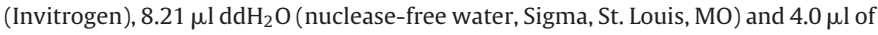
total RNA template $(15 \mathrm{ng} / \mu \mathrm{l})$. All RT reactions were performed in 96 well plates on a thermal cycler (PT-100, MJ Research) under a thermal profile of $25^{\circ} \mathrm{C}$ for $10 \mathrm{~min}$, $50{ }^{\circ} \mathrm{C}$ for $50 \mathrm{~min}$, and $85^{\circ} \mathrm{C}$ for $5 \mathrm{~min}$.

Taqman primers and probes for real-time quantitative RT-PCR assays were designed to the putative pupfish VT/IT receptor sequences obtained above, and to pupfish pro-VT (Lema et al., submitted for publication; GenBank accession no. GU138978), using Primer Express software (Applied Biosystems, Inc.). Primers and probes for all quantitative RT-PCR reactions were synthesized by Integrated DNA

(C) -165 agctccgtgttccttgtgtgtgcaacaggtaccttcatagacgcgttagagaagcagtgcacagccoctctggcactggatc 82 tgctagggcgcacagaggggcagtgccatgcacacttcteccgacgcgcttctctaggtggagagaaccactgatgcectg +1 ATGATGGGAACCCCTTCAAACAGCACCGTCCATCCGAACGGATCCGACCCTITGCTAGAAC

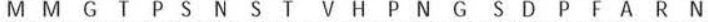
+64 GAGGATGTIGCCCAGATCGAGATCATGGTGCTCAGCATCACCCTGTGGTGGCTGTGATCGGG E D V V A O O I +127 AATGTGAGCGTCCTGCTGGCCATGTACAACACCAAGAAGAAGATGTCCCGGATGCATCTITIT N V S S V L L A A M Y

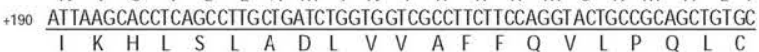
253 IGGAAGATCACCGACCGCTCTACGGGACGGACGCTCTCTGCAGGATAGTGAAGCACCTCCAG

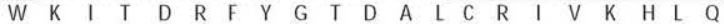
+316 GTGATGGGGATGTITGCCTCCACCTACATGATGGTCATGATGACCTTGGACCGCTACATCGCC +379 ATCTGCCACCCGCTGAAAACCCTCCAGCAGTCCACCAAGCGCTCCTACGTGATGATCATATCC $\begin{array}{lllllllllllllllllllll}\text { I } & C & H & P & \text { L } & K & T & \text { L } & \text { Q } & \text { Q } & \text { S } & \text { T } & K & \text { R } & \text { S } & \text { Y } & \text { V } & \text { M } & \text { I } & \text { I } & S \\ S\end{array}$ T $W$ W I +505 AAAAACGGCTCCGAGGTCTACGACTGCTGGGCGCACTTCATCGAGCCGTGGGGCTCCAAGGCG $K \quad N \quad G \quad S \quad E V A$ Y C W A H F I E P W G S K A +568 TACATCACCTGGATGACCGTGGGGATCTITCTGGTGCCAGTGGTGATCCTCATCCTGTGCTAC $\begin{array}{lllllllllllllllllllll}\text { Y I T } & \text { W } & M & \text { T } & V & G & \text { I } & \text { F } & \text { L } & \text { V } & \text { P } & \text { V } & \text { V } & \text { I } & \text { L } & \text { I } & \text { L } & C & \text { Y }\end{array}$ +631 GGGTTCATCTGCCACAGCATATGGAAAAATATCAAGTACAAGAAAAAGAAGACGGTGGCCGGG G F I +694 GCAGCGGGCAAGAACGGCCTGATTGGGAAGTGTICAGTCAGCAGCATCACAACCATCTCAAGG A A G K N G L I G K C S V S S I T T I S R +757 GCCAAACTCAGGACGGTCAAAATGACTITIGTGATAGTIITGGCCTACATCATCTGCTGGGCG

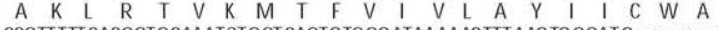
+820 CCGIIITCACGGTGCAAATGTGGTCAGTGTGGGATAAAAAC ITTAAGTGGGATGggtaagtaaca

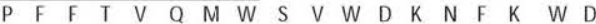
caaaaaaagttacaaattaataaaaataaggatagcagtacacattgtcaaagggaagaaaaaagacgcattcgtttgcgc acagattttacgcacagaaaacagagcaacaattaaaactgcagaaactaaatttattatatttttttaaaatgactcoctg ttctagtagactcgcagcttcacattcagtcaatactatatatggggcccaaaagtgtcgctttttcaatagtagtatttcgtg at aattcaatttctcttataat gcataaatagattct taaatattgaaataagtcttatt taaatctaatt aaatgtaatataat aagagcccaaatgttcatttatttactcaattaaatgtttcttgtatgtat gtatgtatgtatgagttttaaaaataataagtggc tgtgraagtcttttgatgtaaaat acatcttaaacagacagattaaaagcttctgaattctgaat aatagttttttctgaag taagaattgttttattgtatatttgaaaaaaat atatatagatt ttttaagataatattttgacagaaaaacttcacttatt gattttacactgatatttgttttacagtttgaattocagtgcaaacagggccgtat ttaagaagttgctgagctctgggttttg

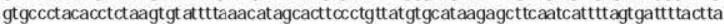
taaaaaatgcattttctccaaaatcgtcttctgatcatagcttgaaatgttcagtttaggcaaaagtcaaatatttaaaactt gaccaagaccttgatgactgagaatcttcatagatatctttgtggttatacttcaaagaggcataaaacagcattacttaaa gacatccatacatt aaagtaccaagaatataattatactccaccagccctgaaagaagagggatggatgtgcttccgttgag cagcggttagcgtgtaggacccatttatggaggccttaatcctogcaatctacatcattatggttattaaacacacaatcttta

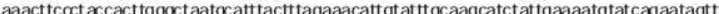
taggtgtgatgccacaagttggcatgttagaaggtccagccagatagtcgaagttagtgaattttacgtatctttacttatgca ggaaactatctcagtgtgataaatttaacataatoccttgactcctgcaaaatttcagaaaaatgtgtttataaaacagtgaa aattttattgatggtattaatacagggggagaatttgaatttgagccaagagtgataaacaccctatacagaacctocacc ctcctccaatataacaccagatgaajttcattacagaggcacttctgcaaccttgagtataccagatgtttttggattaatc atttcttoctctctcoctctgtctgttocacag

+874 AITCTGAGAACACAGCAGTGTCTCTGTCTGCGCTCCTTGCCAGTCTCAACAGCTGCTGCAAC

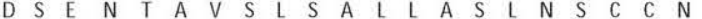
+937 CCGTGGATATACATGATCTITAGCGGCCACCTTCTCCAGGATTTCATGCACTGCTTCTCCTGC P W I Y M I F S G H L L Q D F M H C F S C +1000 TGCCGAAAACTAAACGCTGACTACAAGAAGGAGGACTCGGACAGCAGCATCCGCAGGACGACG $\begin{array}{lllllllllllllllllllll}C & R & K & L & N & A & D & Y & K & K & E & D & S & D & S & S & I & R & R & T & T\end{array}$ +1063 TTACTGACCAGGATCACCAATCGGAGCCCGACGGGCAGCTCCAGCAACTGGAGAGAGCTTGAT

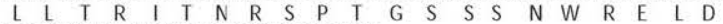
+1126 AACTCCCCAAAAACATCAGCTCAGACAGAGTAAlacaggcagtagctocaagaaacacatgtagagtgagcto

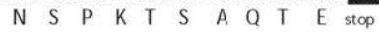

+1198 agcatgcaggattaggactaaaagttccacaaactttaaaattctaatgactaggaggcatttgctt

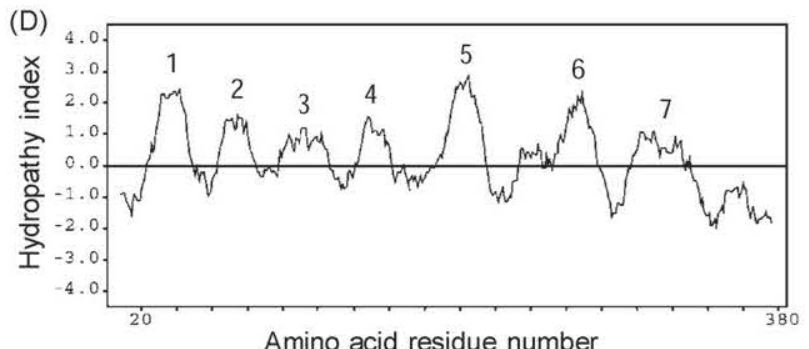

Amino acid residue number

Fig. 1. Cyprinodon nevadensis amargosae V1a1 (GenBank accession no. GQ981412) (A) and V1a2 (GQ981413) (C) cDNA receptor sequences and their conceptual translation. Transmembrane segments predicted using MEMSTAT (http://bioinf.cs.ucl.ac.uk/psipred/) are underlined in the nucleotide sequence. Start and stop codons are highlighted in black. Introns located in the V1a1 (GU014233) and V1a2 (GU014234) receptor genes are also shown as lowercase regions of nucleotide basepairs within the open reading frame. Kyte-Doolittle hydrophobicity plots illustrating the seven transmembrane domains for the V1a1 (B) and V1a2 (D) vasotocin receptors. 
(A)

+1 ATGGAaAgGatCAgGGTAGAaACAGACTGGGATGgaTtAGgTCICTCCTCTCCAGGCGCCTCC

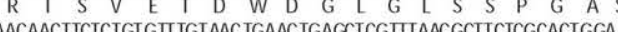
E G N N F S V F F V T E L S S S F N A S R T G +127 GGATCCATCTTIGGTATCTTTCAAGAGAATGGCTCCAACACCACGCCTCACTCCCTGCCTCA T T P H S L P Q -190 CCCCGGACCAGGGACCAAGGACTGGCCCGGGCTGAGATCGCCGIIT GGGGATGG TCTGGCI +253 CTCACCACCCTGGGCAACAGCTTCGTGTTGTGGGTCCTTCTGAGGAGAAGAAAGCACAATGCA L $T$ T $T$ T L L .316 CCTATGCACCTGTITATGGTCAACCTITGTGTGGCTGACCTGGTGGTGGCTCTCTTTCAGGTA P M H L F M V N L C V A D L V V A L F O V +379 CTGCCTCAGCTGATATGGGACATAACAGAGAGGITTCAGGGGCCTGACTTGCTCTGCCGGTCC 442 GTCAAGTACTIGCAGATAGTGGGGATGITTGC TTCCTCCTACATGATAGTTGCCATGACAGTC

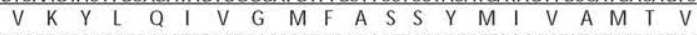
+505 GACCGGCACCATGCCATCTGCTGCCCACTGCAGGCTIACCGCGMGGAGCTATGTCCCGCTGG A

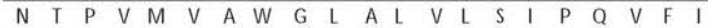
.631 IICTCCCGCTCAGAAGTAGCGCCAGGAGAGTITGAGTGCTGGGGTCACTTCACTGAGCCGTGG F S R S E V A P G E F E C W G H F T E P W +697 GGGCTGAAGGCCTACGTCACCTGGATCACCGTGGCTGTGTTCCTGCTGCCCGCCCTCATCATI

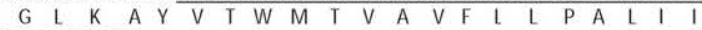
+757 ACCATCTGTCAGgtaatactggttgcaccogctgcttccetgcagogtacgctgactattgataacaggattacatgct T I $\quad$ C $\quad$ Q

caaaaaaactcatcaggtaatgatgcatatggcatgaaagaaatgcaaagtgcađtggcagøcattgcccaacagcoc at gggatgctgcaattggtgtaaggtggtgaacagacattctggactgcctcocaccggtcctgctctatttggggaaagata ttcaagagtctggccgtttctcoctaattaaagagcttgaggcggctgcccactctgagagogatct gccaggatgtggaac atatgcgatctcaaccgacttcacaatcagtaacctagttcttgatattgcatttgattcaagaagagtattttacacacaca ggctttcaaagtgattacccuttaaatgcttctcttatttaaatattagcagctgatcacatatctcocttctcatatataaa agtaacttttocccocctacagtttaaactaatgtcttagaggggaatgtaataaaaa aaggcttagaccagttaaatga tagtttctgaattacctttgactcagcttcactgcattatacggggtctctatcaagatgctacatđtgtcttgaaattgct cocctctctgccttcaactgocaaactcagagaacatctctttccatagttctctttaggtgactcaaatccagttcactcatg tagttcataaaaaaaaaaacagcaagcttacccaaactggtgtctctgattgtctagtggtcaggactcagcactcœggg ttcgattccgggtcagggaagttgtattgggtcaccaactggtggcttgatgttaccctttaaagggaagtgttaccctagtgg ttagagcagtacg cttgtgcttaaaacacaacagcctgcaatctgggttcctgagcaagacocttaacccaacactgctocct gggtgccatactatggcagoccactgctccccaagggggtgggttaa aatgaagagagtgaatttocccattatgggacas aaagggatttacattcacagaaataagatatgaataaagataaaaccaattcataaaatctgtgttacaacactccaaaa ttgaacagaaaaaaagaccatgtcttgtccacgtocctgttttdtaatgtcattg tgtcatagtataaaaattctataaaa taaaataaattacttatctaaggtggaaaaaaagactgaaaacattaggatggtcttgcttttacaacacagggttatgtgca cattgagaggcaataaatgtaggaattgaagoctgcaaaaatattaatgaagtaagocttagagaatttagtggattagct ctatgactttggatggagctgggaatgtcagactataaaatcctttcagtgattttcagattttcttgaaaaggaaaagtgg agccaatttcagcaocataaaatttcatagacacctttctctaaggcagtaaagatataaacctgtttagttatgctacttaaa ggttcagagacagtttaattgtagatgactgataccaactcagctgtatctcatgttcttcataataatgttttoctctact cctggcacgtggtaacagtaaaactcatctggatttggatattaatggoctcct at aattgctgtctttcag

+769 ATAAGAATCTTCCGCGAGATI CACAACAACATCTACCTGAAGTCAGAGAGGATAGTGATGGCT I R I F R E I H N N I Y L K S E R I V M A +832 GAGCTGAAAAGGAGTGAAAACCTGTTTCGCATCCACGGCTTTAGGACAGAGGAGGACCGGGCA

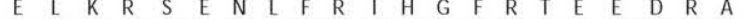
+895 AGGGAAAGGGAGAGGGGAAGACAGGTGCCTGGCAGAGGAGGAGGAGGACAACTGCTGAAGGAC

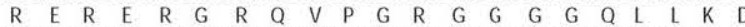
+958 AGCAATTTACATGACTGCGAAGTGGGACAACATTACGACTATGTGCCGTCTGTTATTCAATA S N N L L H +1021 AGTAGCTGCTGCGGTCAGACAGAAGgAaCATCATTATCGCAAGAGCAAATACCAAAGGGCTCC $\begin{array}{lllllllllllllllllllll}S & S & C & C & G & Q & T & E & G & T & S & L & S & Q & E & Q & \text { I } & P & K & G & S\end{array}$ +1084 GATTTCCGGGAGTCCTGTACCACTTTCCCCGCTGTTCCCTGGACTGTGCCCCCCCTCCACAT

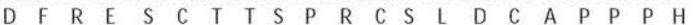
+1147 CCAGTCACTCCACCTCACAGTATCACTAAAGCCATGTCCAAGACAGTGAGGATGACTCTAGTI

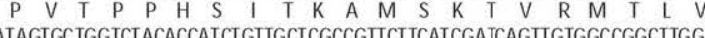
+1210 ATAGTGCTGGTCTACACCATCTGTTGCICGCCGTTCTTCATCGATCAGTTGTGGCCGGCTTGG I V L V Y T Y C S P F +1273 GATCCAGACCCTCCAGCCAAGGAGT +1336 ICATGCACCAACCCGTGGATCTACACGGCCTITCCAGCAGCGTGTCCAGAGAGCTTCAAAAC $\begin{array}{lllllllllllllllllllll}\text { S } & C & T & N & P & W & \text { I } & \text { Y } & \text { T } & \text { A } & F & S & S & S & V & S & R & E & L & Q & N \\ \end{array}$ +1399 CTGCTGCAGTGCCGG TCACGTCTCGGCCGACGGGGCTCCCTCCCCGATGACTCTACGGCCACA

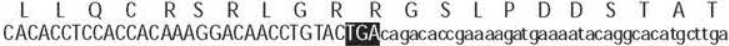

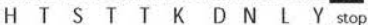

+1533 aaaacacatggcgagttagctgcaaggactgatgcagoctgtagttcatgcatcacagcctgggaacagcctgacctctacc +1615 agatgtt tgctttgacaaaggacagctgtacoctcagcaggacatccatctgtgctcacctgtctactcagoccccgoccctct +1699 acctaccagaaggatgtcattgacaatgtcaacaccacacacagtccagctctcttgcatctgcaatgcaaaatgatctgg +1781 aaagt aaagagattttcact tcagtagcttttggcttggatctcgtggagtgattcatgtgaggaaaataaaaagaaaacac +1863 tgtctgactccaacactgcagagaacacaaggaatgcaaaggatggatagctgcatttatttgctcgtggcatggctaatgc +1945 acaaaagcatcagataaagcttcggatctagagggacgcaaacagcaatatttgaaattgctgcagctataagttgggtoct +2027 aaaccaaggtgaaaatttttttatgttaattaaagatcagagactgaattcacactggaatcactctgaaggatttcttcaga +2111 agacggatgtatattcactcctgaggatggcgtattgaaagtaaacacagagccctgcaagaaagct gcagaaataaaca +2192 tctcttagaaaacttc-polyatai

(B)

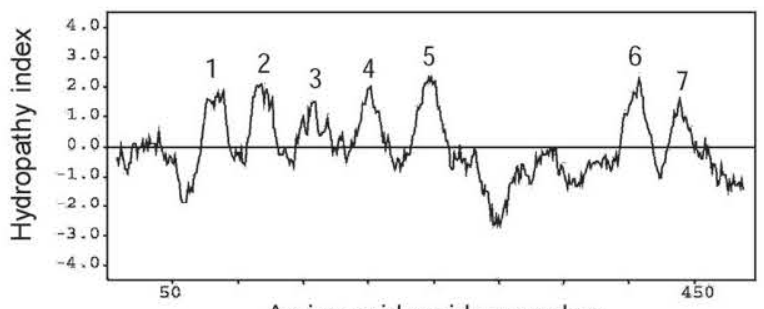

Amino acid residue number
(C)

413 gagaagacatggccttcatcatctocatgttgcttgctagccttaacagttgctgtaatoctggatctatatgattttgocg 329 gtcaoctgttccatgacctgataaagagcttctgctgctgctgcagaaactatgttgcagactcatoctgccaagtcaatcag 246 gagtgcaggcacaagatagatacagttgttogcagagcgaggcagagtgaagctacctcaggcaaaaacgcagcaaatca 166 tttoctgacagcccatcctttgtaagaatgttacattggagcaacagacgacagaaagacaactattcatggtgtaaactga

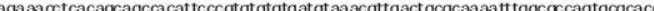
ATGGATGAACTIITATCCGCACAAGATGCIIGGCITCAGAACTITICCTATIGTACTACAGT D E L L S A O D A W CATTIAAACAAGACTCATCCAGGGAACAACGTGGTAAACCCITIAAAGCGAAACGAAGAAGTG $H L N$ K T H P G N N V V N P L K R N E E V +127 GCCAAAGTGGAAGTTACTGTCCTGGTGCTGGTGCTITT GCTGGCTCTGACGGGTAACCTGTGC $\begin{array}{lllllllllllllllllllll}A & K & V & E & V & T & V & L & V & L & V & L & L & L & A & L & T & G & N & L & C\end{array}$ 190 GTCTGTGGGCTATCCACACCACCAAGCACAGCAAGTCTCGGATGTATACTTCATGAAGCAC $\begin{array}{lllllllllllllllllllll}V & L & W & A & \text { I } & H & T & T & K & H & S & K & S & R & M & Y & Y & F & M & K & H\end{array}$ 253 CTGAGCATCGCAGATCTTGITGTGGCCGTITITCAGGTCCTGCCGCAACTCATITGGGACATA

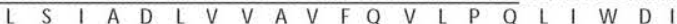
316 ACATTTCGC TITTACGGACCAGATATTATCTGCAGGCTCGTCAAATACCTCCAAGTGTGGGC $\begin{array}{lllllllllllllllllllll}T & F & R & F & Y & G & P & D & I & I & C & R & L & V & K & Y & L & Q & V & V & G\end{array}$ *379 $\frac{\text { ATGTIT GCGTCCACCTACATGCTGGTCCTGATGTCCATCGATAGATGTTAGCAGTCTGCCAG }}{\mathrm{M} \text { F A S T Y M L V L M S I D R C L A V C Q }}$ 442 CCGCTTCGCTCTGTGCACAAGGGGAAAGATCGCTTCTGTGTCATCGGATCCTGGATCCTCAGI P L L S V H K G K 505 CTGGTGTTCAGCACCCCACAAGCTTACATCTITTCTCTCAGGGAGGTCGGGAATGGCGTCTAC 568 GACTGCTGGGGGGATTICGTGCAACCCTGGGGTGCAAAAGCCTACATCACATGGATGAGTCTG

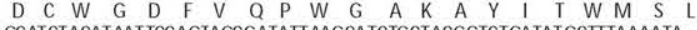
+631 AGCATCTACATAATTCCAGTAGCGATATTAAGCATCTGCTACGGTCTGATATGCTITAAAATA $\begin{array}{llllllllllllllllllll}S & \text { I } & Y & \text { I } & \text { I } & P & V & A & \text { I } & L & S & \text { I } & C & \text { Y } & G & \text { L } & \text { I } & C & F & K\end{array}$ .697 TGGCAGAATATTAATATGAAAACCAAGAGGGAGCACTIIITGGCTCTGACGCCGAGGCCGTCC

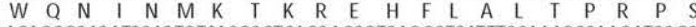
757 AAGAGCGCACATCCACTGTCACGCGTCAGCAGCGTCAGGCTCATTTCCAAAGCCAAGATCCGC K S A H P L S R V S S V R L I S K A \begin{tabular}{l} 
+820 ACGGTGAAAATGACATTTGTGGTGGTATTGCTIACATCGTATGCTGGACTCCTITTCTT \\
$\mathrm{T} \vee \mathrm{K}$ \\
\hline
\end{tabular} +883 $\frac{\text { GTTCAGATGTGGTCTGCATGGGATCCAGCTGCACCAAGAGAAGACATGGCC I CATCATCTCC }}{\mathrm{V} Q \mathrm{M} \mathrm{W}} \mathrm{S}$ A W D A A P R D M A F I S 946 ATGTTGCTTGCTAGCCTIAACAGCTGCTGTAATCCCTGGATCTATATGCTITTGCCGGTCAC

M L L L A S $\rightarrow 1009$ CTGTTCCATGACCTGATAAAGAGCITCTGCTGCTGCTGCAGAAACTATGTTGCAGACTCATCC

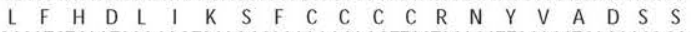
+1072 $T$ GCCATCTCACAAGCAGTGCAGGCACAAGAGAGGTTCCTCCACGTTCGACATCAAAAACGGC $\begin{array}{lllllllllllllllllllllllllll}\text { C } & H & \text { V } & N & \text { Q } & E & C & R & H & K & R & G & S & S & T & F & D & \text { I } & K & N & G\end{array}$ .1135 AGCAGTATGAGGAGCTIGACTCACACATCCAGCCTGGGGGGACCCACACACTGAactggocaaa

$$
\begin{array}{lllllllllllllllllllllllll}
S & S & M & R & S & L & T & H & T & S & S & L & G & G & P & T & H & \text { stop }
\end{array}
$$

+1200 gtctaaagctccctgtggttgacttggtgcagcaatccttcaaaattttgatttaggctttaatcatcttcagcagaactgagct +1286 tgccttgtcaaatacagtatattaaactcagtcaaacagagaacataaacctcctgtctggaaaggactttgcacoctatgata +1370 acagaaagtagaacaaaacaacattttatocaaaatgttaactaaatgggctgcaaagaaaggttccaaacagagcctgat +1451 ctggtgcacatttcaacatggcagtgttcaaatattcoccaacagctgctgcatoccaact ggactgggcacaatagaccaga +1534 tttrgattgatgaagttgaaaatgttagctgtgaaggcagaggaagttaaatgtataaggttgtgagaagggacatgtttatg +1617 tatctgtaaaagtacctagaaaaagacaagagactatttactgaatctttagattgctagacttgtctactatctcttaagttaa +1702 ttcacatataaacattctttagatatgtt gttttgctcttcagatttatatttagatatattaactatagttgcttgcaaaggtt +1790 gtgctttggtaattagtcatcagagatgocaagttttccacaacagaataaggtacaccaaaacttttgaaaaat- polveail

(D)

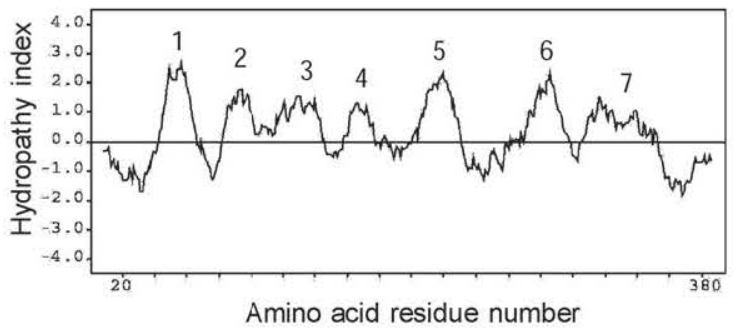


Technologies (Coralville, IA) and are provided in Table 2. When possible, primers for quantitative RT-PCR reactions were designed to span an intron. Selected real-time RT-PCR products for each of these primer sets were sequenced to confirm specificity of the primer and probe sets.

Quantitative RT-PCR reactions were run in $25 \mu$ l volumes with each reaction containing $12.5 \mu$ l Master Mix (ABI Universal MasterMix Reagent), $0.5 \mu$ l forward primer $(45 \mu \mathrm{M}), 0.5 \mu \mathrm{l}$ reverse primer $(45 \mu \mathrm{M}), 0.5 \mu \mathrm{l}$ probe $(10 \mu \mathrm{M}), 8.0 \mu \mathrm{l} \mathrm{ddH_{2 } \mathrm { O }}$ (nuclease-free water, Sigma) and $3.0 \mu$ l of reverse-transcribed cDNA template. Reactions were run on an ABI 7500 Sequence Detector under a PCR thermal profile of $50^{\circ} \mathrm{C}$ for $2 \mathrm{~min}, 95^{\circ} \mathrm{C}$ for $10 \mathrm{~min}$, and then 38 to 45 cycles of $95^{\circ} \mathrm{C}$ for $15 \mathrm{~s}$ and $60^{\circ} \mathrm{C}$ for $1 \mathrm{~min}$. Serial dilutions of total RNA from the experiment were used as a standard curve reference. Samples comprising the standard curve were run in triplicate, and all experimental samples were run in duplicate (average $\% \mathrm{CV}=0.56 \%$ ). For each gene measured, DNA contamination was assessed by analyzing a total RNA sample that was not reverse-transcribed, and each run included duplicate samples lacking cDNA template to further control for contamination. $E F-1 \alpha$ was also quantified as a normalizing gene. Mean $E F-1 \alpha$ transcript abundance was stable across all salinity treatment groups. Correlation coefficients $\left(r^{2}\right)$ for the standard curve of each gene ranged from 0.989 to 0.996 . PCR efficiencies for each transcript were calculated by the following equation: efficiency $=-1+10^{(-1 / \text { slope })}$, and are provided in Table 2 .

Relative VT and IT receptor mRNA expression was subsequently calculated using the serially diluted standard curve, normalized to EF- $1 \alpha$ mRNA expression in that tissue, and expressed as a relative level by dividing the resulting values to the mean of the designated control group within each sampling time ( $5 \mathrm{~h}$ or $20 \mathrm{~h}$ ). Normalization of transcript abundance values was conducted within each sampling time because it was found that the pupfish hypothalamus exhibits diel variation in proVT and VT/IT receptor transcript abundance (Lema et al., submitted for publication), which makes the effects of salinity treatment difficult to distinguish when plotted without normalization. Statistical comparisons of mRNA levels were carried out within each sampling time ( $5 \mathrm{~h}$ and $20 \mathrm{~h}$ ) using one-factor ANOVA models, or a Welch ANOVA model when variances failed to conform to assumptions of normality even after transformation (Zar, 1996). When these models revealed a significant difference, pairwise comparisons were performed between each salinity treatment group and its respective control group using Dunnett's tests. All data are presented as mean \pm SEM, and sample sizes $(n$ ) for each treatment group are provided in the appropriate figures.

\section{Results}

\subsection{Isolation and sequencing of two distinct V1a-type receptors from C. n. amargosae}

Two cDNA fragments encoding putative pupfish VT receptors were identified using RT-PCR with degenerate primers designed to other teleost VT receptors. BLAST analysis of these two fragments confirmed that both cDNAs shared high sequence similarly with VT receptors identified previously in other teleost fishes, but indicated that these two pupfish cDNAs were substantially different from each other. BLAST analysis of the two partial cDNAs revealed greatest homology with two VT receptor gene sequences from puffer (Takifugu rubripes, Genbank accession nos. AY027886 and AY027887), suggesting the isolation of two distinct pupfish VT receptor transcripts. Subsequent sequencing of full-length coding regions for these two pupfish cDNAs was conducted using $5^{\prime}$ - and 3'-rapid extension of cDNA ends (RACE) PCR. The first full-length cDNA transcript, named V1a1 (GenBank accession no. GQ981412), was 1634-bp nucleotides in length with a 1236-bp nucleotide open reading frame encoding a predicted protein of 412 amino acids (Fig. 1A). Examination of the secondary structure for this predicted protein revealed the presence of seven transmembrane domains (Fig. 1B), which is structurally characteristic of class A membrane receptors including all VP/VT receptors. The second full-length transcript, named V1a2 (GenBank accession no. GQ981412), was 1429-bp nucleotide in length with a 1155-bp open reading frame encoding a deduced protein of 385 amino acids (Fig. 1C). Analysis of the secondary structure of this deduced V1a2 protein again indi- cated the presence of seven hydrophobic transmembrane helices (Fig. 1D). Full-length PCR using primers designed to the UTRs of each cDNA amplified two V1-type receptor genes: one contained a 460-bp nucleotide intron and encoded the V1a1 transcript (GenBank accession no. GU014233), and a second for the V1a2 transcript that included a 1555-bp intron (GU014234).

\subsection{Isolation and sequencing of a teleost V2-type VT receptor CDNA}

Degenerate primer PCR identified a partial cDNA fragment for a V2-type receptor from C. $n$. amargosae. Extension of this partial cDNA generated a 2230-bp full-length cDNA with an open reading frame of 1491-bp nucleotides encoding a predicted protein of 497 amino acids (GenBank accession no. GQ981414) (Fig. 2A). Subsequent analysis of the secondary structure for the deduced pupfish V2-type receptor protein again revealed the presence of seven transmembrane domains (Fig. 2B). Full-length PCR and subsequent sequencing using gene specific primers designed to the $5^{\prime}$ and 3'-UTRs of this V2 cDNA identified a gene of 3679-bp, with a 1727-bp intron located in the open reading frame (GenBank accession no. GU014235).

\subsection{Isolation and sequencing of the isotocin receptor from C. $n$. amargosae}

To demonstrate that C. n. amargosae contains a distinct IT receptor mRNA in addition to the three VT receptor cDNAs identified above, degenerate primer PCR was used to isolate and sequence a partial cDNA fragment for the IT receptor. Extension of this initial cDNA fragment by RACE PCR generated a full-length transcript of 2295-bp nucleotides containing an 1185-bp nucleotide open reading frame encoding a deduced sequence of 395 amino acids (Fig. 2C) that showed high homology to the IT receptor from white sucker (Catostomus commersoni) (Hausmann et al., 1995). Secondary structural analysis of this predicted protein indicated the presence of seven hydrophobic transmembrane domains (Fig. 2D). As above, full-length gene specific primers were designed to the $5^{\prime}$ - and 3'-UTRs of this Amargosa River pupfish IT receptor (ITR) cDNA(GenBank accession no. GQ981415), and used to isolate and sequence the ITR gene from pupfish genomic DNA (Genbank accession no. GU014236).

\subsection{Sequence comparison and phylogenetic analysis of teleost VT and IT receptors}

Alignment of predicted amino acid sequences for the Amargosa pupfish V1a1, V1a2, V2, and ITR cDNAs indicated closest structural similarity between $V 1 a 1$ and $V 1 a 2$, although all four putative receptors showed high homology in transmembrane domains 2 , 3, 6 and 7 (Fig. 3). Comparison of amino acid sequences likewise revealed strongest identity (69.7\%) between the V1a1 and V1a2 pupfish receptors, and both of these receptors showed high identity to previously identified VT receptors from other Actinopterygian fishes (70.6-85.2\%) (Table 2). The pupfish V2 receptor showed considerably lower sequence identity to the V1a1 and V1a2 receptors (33.0-34.0\%), as well as to previously described VT receptors from other teleosts (31.7-33.5\%). This pupfish V2 receptor did, however, show greater amino acid sequence identity to V2-type receptors

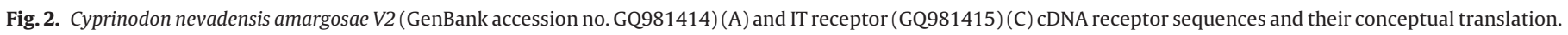

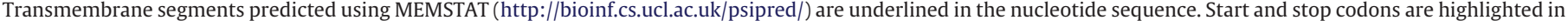

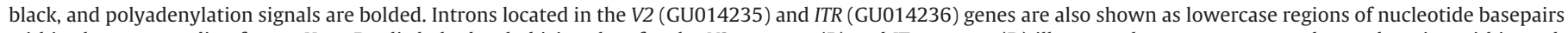

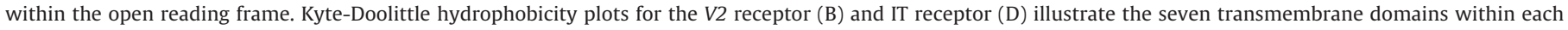
receptor protein. 


\begin{tabular}{|c|c|c|}
\hline V1a1 & $-----------------M L C S S E I S C N I T E V F N L T Q K Q E----I G A A G S A R N L S G K T N$ & 37 \\
\hline V1a2 & ------------------------------------------ MMGTPSNSTVHPN & 13 \\
\hline ITR & $-------------------------M D E L L S A Q D A W L Q N F S----Y C N Y S H L N K T H P G N N$ & 31 \\
\hline \multirow[t]{3}{*}{ V2 } & MERISVETDWDGLGLSSPGASEGNNFSVFVTELSSFNÄSRTGGS IFGIFQENGSNTTPHS & 0 \\
\hline & : & \\
\hline & ICL I & \\
\hline V1a1 & DTDPFGRNEEVAKIEITVLSLAFVAAVVGNLSVLLAMYRSRRKLSRMHLFMKHLSLADLV & 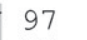 \\
\hline V1a2 & GSDPFARNEDVAQIEIMVLSITLVVAVIGNVSVLLAMYNTKKKMSRMHLFIKHLSLADLV & \\
\hline ITR & VVNPLKRNEEVAKVEVTVLVLVLLLALTGNLCVLWAIHTTKHSKSRMYYFMKHLSIADLV & \\
\hline \multirow[t]{2}{*}{$\mathrm{V} 2$} & LPQPRTRDQGLARAEIAVLGMVLALTTLGNSFVLWVLLRRRKHNAPMHLFMVNLCVADLV & \\
\hline & 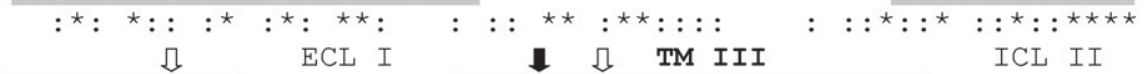 & \\
\hline V1a1 & VAFFQVLPQLCWEVTFRFYGPDFLCRIVKHLQVLGMFASTYMMVMMTLDRYIAICHPLQT & \\
\hline V1a2 & VAFFQVLPQLCWKITDRFYGTDALCRIVKHLQVMGMFASTYMMVMMTLDRYIAICHPLKT & \\
\hline ITR & VAVFQVLPQLIWDITFRFYGPDI ICRLVKYLQVVGMFASTYMLVLMSIDRCLAVCQPLRS & \\
\hline \multirow[t]{3}{*}{$\mathrm{V} 2$} & VALFQVLPQLIWDITERFQGPDLLCRSVKYLQIVGMFASSYMIVAMTVDRHHAICCPLQA & \\
\hline & 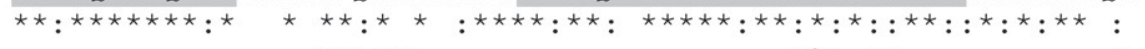 & \\
\hline & TM IV $\quad$ ECL II & \\
\hline V1a1 & LQQ-PTRRAYIMISSTWACSLVLSTPQYCIFSLSEVRPGSAVYDCWGHFVEPWGPRAYIT & \\
\hline V1a2 & LQQ-STKRSYVMIISTWICSLVLSSPQYFIFSMSEIKNGSEVYDCWAHFIEPWGSKAYIT & \\
\hline ITR & VHK-GKDR--FCVIGSWILSLVFSTPQAYIFSLREVGNG--VYDCWGDFVQPWGAKAYIT & \\
\hline \multirow[t]{2}{*}{ V2 } & YRVGAMSRWNTPVMVAWGLALVLSIPQVFIFSRSEVAPG--EFECWGHFTEPWGLKAYVT & \\
\hline & 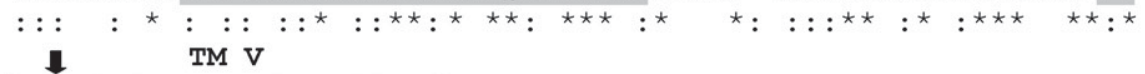 & \\
\hline a1 & WITAGIFLVPVAVLVFCYGFICRAIWRNLKCKTR------------------------- & \\
\hline $\mathrm{V} 1 \mathrm{a} 2$ & WMTVGIFLVPVVILILCYGFICHS IWKNIKYKKK------------------------- & \\
\hline ITR & WMSLSIYIIPVAILSICYGLICFKIWQNINMKTK------------------------- & \\
\hline \multirow[t]{2}{*}{ V2 } & WMTVAVFLLPALIITICQIRIFREIHNNIYLKSERIVMAELKRSENLFRIHGFRTEEDRA & \\
\hline & 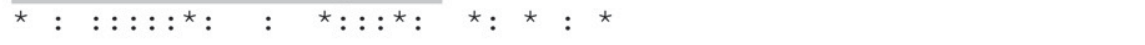 & \\
\hline \multicolumn{3}{|l|}{ V1a1 } \\
\hline & ------- & \\
\hline ITR & 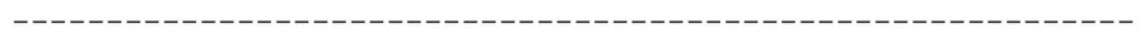 & \\
\hline \multirow[t]{2}{*}{ V2 } & RERERGRQVPGRGGGGQLLKDSNLHDCEVGQHYDYVPSVIQYSSCCGQTEGTSLSQEQIP & \\
\hline & ICL III & \\
\hline & -----RKSADAVVEATKSGILGRSSVSSVSTISRAKLRTVKMTFVIVVAYVVCWAPFFTV & \\
\hline $\mathrm{V} 1 \mathrm{a} 2$ & $-----K T V A G---A A G K N G L I G K C S V S S I T T I S R A K L R T V K M T F V I V L A Y I I C W A P F F T V$ & \\
\hline ITR & -----REHFLALTPRPSKSAHPLSRVSSVRLISKAKIRTVKMTFVVVIAYIVCWTPFFFV & \\
\hline \multirow[t]{3}{*}{ V2 } & KGSDFRESCTTSPRCSLDCAPPPHPVTPPHSITKAMSKTVRMTLVIVLVYTICCSPFFID & \\
\hline & 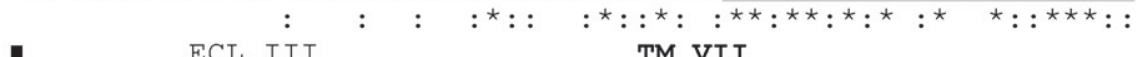 & \\
\hline & $1 \quad$ ECL III $\quad$ TM VII & \\
\hline V1a1 & QMWSVWDKTFSWDDSENTAVSLSALLASLNSCCNPWIYMTFSGHLLQDFMHCFSCCYRLR & \\
\hline V1a2 & QMWSVWDKNFKWDDSENTAVSLSALLASLNSCCNPWIYMIFSGHLLQDFMHCFSCCRKLN & \\
\hline ITR & QMWSAWDPAAPRE---DMAFI ISMLLASLNSCCNPWI YMLFAGHLFHDLIKSFCCCCRN- & \\
\hline \multirow[t]{2}{*}{ V2 } & QLWPAWDPDPPDQ---GVAFTILMLLASLNSCTNPWIYTAFSSSVSRELQNLLQCRSRLG & \\
\hline & 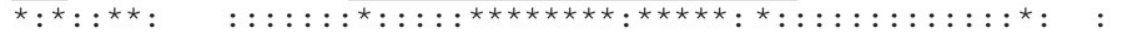 & \\
\hline V1a1 & DKLKKQDSDSSIRRTTLLSRLQG---PRLSKPFRELNYTIKNCPQATPAS 412 & \\
\hline V1a2 & ADYKKEDSDSSIRRTTLLTRITNRSPTGSSSNWRELDNSPKTSAQTE--- 385 & \\
\hline ITR & ---YVADSSCHVNQECRHKRGSSTFDIKNGSSMRSLTHTSSLGGPTH--- 395 & \\
\hline \multirow[t]{2}{*}{ V2 } & RRGSLPDDSTATHTSTTKDNLY---------------------------- 497 & \\
\hline & : : : : : : : : : : : & \\
\hline
\end{tabular}

Fig. 3. Sequence alignment for amino acid residues of the V1a1, V1a2, V2 and ITR cDNAs identified from Amargosa pupfish. Putative transmembrane helices (TM I-TM VII) for each receptor were predicted using MEMSTAT (http://bioinf.cs.ucl.ac.uk/psipred/) and are delimited by gray boxes. Intracellular loops (ICL) and extracellular loops (ECL) are also illustrated. Consensus between the sequences is indicated by asterisks (four identical residues) or by double dots (conservation between the V1a1 and V1a2 paralogs). Conserved residues shown to be important for receptor binding to the VT/IT peptides are marked by arrows. Black arrows indicate conserved residues that form a hydrophobic cleft in the receptor; white arrows indicate residues that form a lipophilic pocket; and gray arrows indicate residues that are involved in specific stacking interactions.

from lungfish and amphibians (44.5-47.4\%). The comparatively low sequence identity between the pupfish V2 receptor and V2type receptors from other vertebrates results from an elongated intracellular membrane domain (ICL III) located between transmembrane helices 5 and 6 in the pupfish $V 2$ receptor (Fig. 3). This elongated intracellular domain is not present in either the V1a1 or V1a2 receptor (Fig. 3), nor in any other previously identified teleost VT receptors.
A phylogenetic tree comparing amino acid sequences for the pupfish V1a1, V1a2, V2, and ITR to VP/VT and OT/MT/IT receptors from other vertebrates, as well as to VP/VT-like receptors from invertebrates, is shown in Fig. 4. This phylogeny revealed that the vertebrate VP/VT and OT/MT/IT receptors clustered into four distinct clades: V1a-type VP/VT receptors, V1b-type VP/VT receptors, OT/MT/IT-type receptors, and V2-type VP/VT receptors (Fig. 4). The newly identified pupfish $V 1 a 1$ and $V 1 a 2$ receptors belonged 


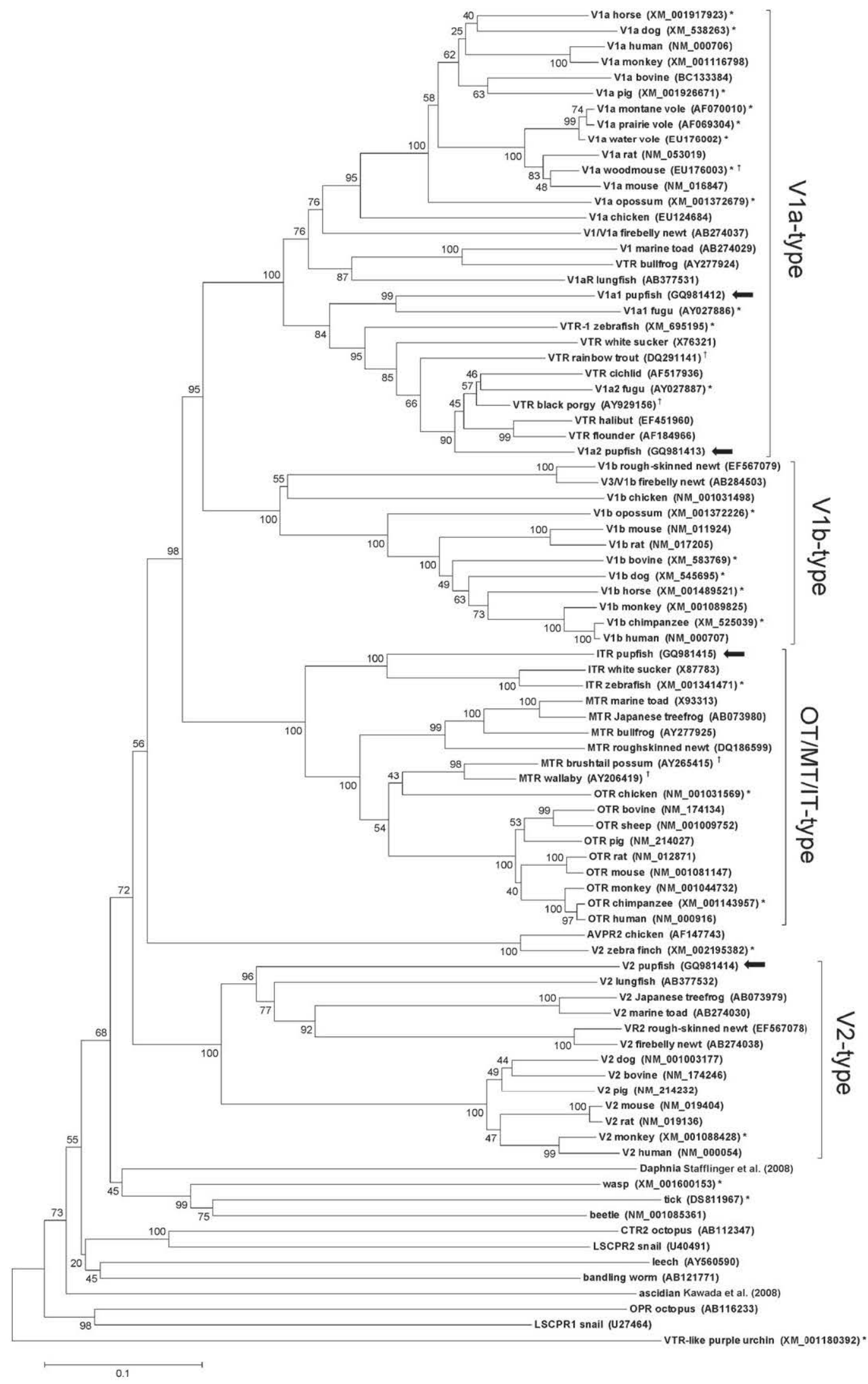

Fig. 4. Phylogentic tree based on alignment of deduced amino acid sequences for vasopressin/vasotocin and oxytocin/mesotocin/isotocin receptors from vertebrates, and for related neuropeptide receptors from invertebrates. Tree was assembled with the neighbor-joining method with pairwise deletion, and bootstrap values from 1000 replicates are indicated at each node. GenBank accession nos. for each sequence are provided following the taxon designation. Arrows indicate the receptors encoded by the pupfish V1a1, V1a2, ITR and V2 cDNAs ( ( $\dagger$ ) partial protein sequence only; $\left({ }^{*}\right)$ receptor amino acid sequence predicted from genomic DNA) (See Refs. Kawada et al., 2008; Stafflinger et al., 2008). 


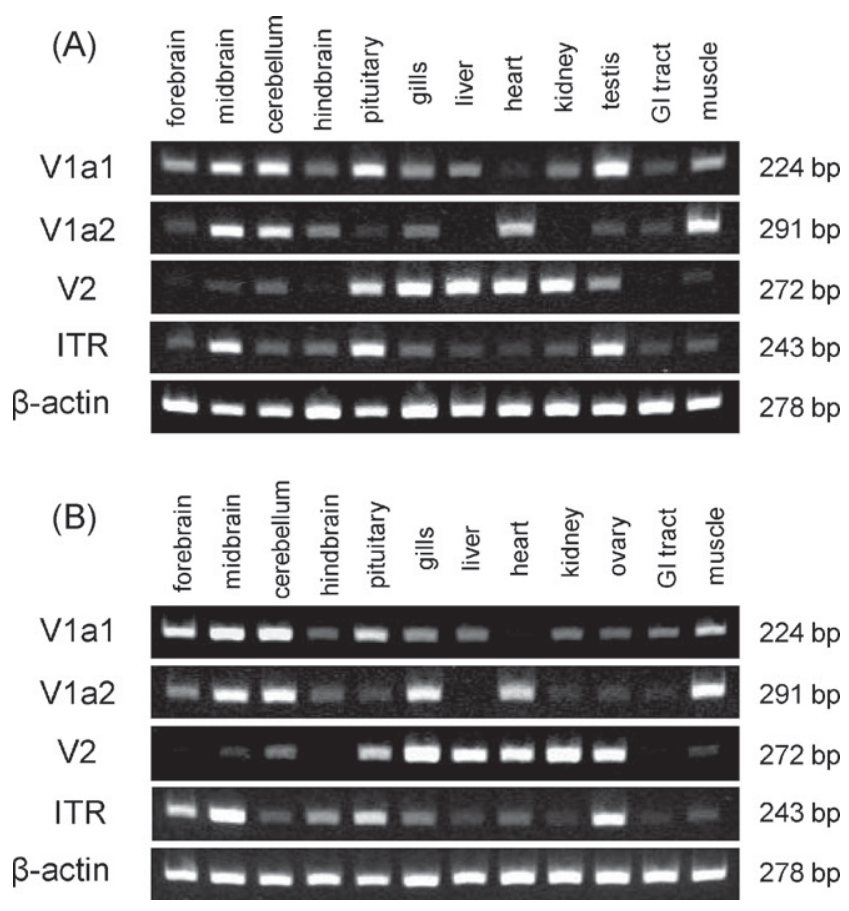

Fig. 5. Distribution of VT receptor (V1a1, V1a2 and V2) and IT receptor mRNAs in the tissues and organs of the male (A) and female (B) Amargosa pupfish. RTPCR products were analyzed by electrophoresis on a $2 \%$ agarose gel with ethidium bromide staining. PCR product sizes for each transcript are provided.

to the V1a-type VP/VT clade, while the pupfish ITR deduced protein grouped within the clade comprised of all vertebrate OT/MT/IT receptors. The pupfish $V 2$ receptor likewise grouped within a clade containing the V2-type receptors from mammals, amphibians, and lungfish. Interestingly, however, the two avian V2-type receptors identified to date - a VT receptor cDNA from chicken (GenBank accession no. NM_001031479 and AF147743) and a putative V2type VT receptor gene from zebra finch (Genbank accession no. XM_002195382) - do not group within this same V2-type receptor clade, suggesting that these described avian VT receptors may instead belong to a previously unrecognized class of VT receptors distinct from teleost, amphibian and mammalian V2-type receptors (Fig. 4).

\subsection{Comparison of tissue expression patterns for VT and IT receptor $m R N A s$}

Receptor mRNA transcript levels, as indicated by RT-PCR, varied among organs and tissues (Fig. 5). V1a1 mRNAs were most abundant in the midbrain (optic tectum and hypothalamus), cerebellum and pituitary gland of both sexes. V1a1 transcripts also showed a distinct sex difference in gonadal expression, with V1a1 mRNAs abundant in the testis but not the ovary $(t=6.756, p=0.003)$ (Fig. 6$)$. The expression pattern of the V1a2 receptor was distinct from that of the V1a1 receptor, with expression highest in the midbrain, cerebellum, heart and skeletal muscle (Fig. 5). A fainter amplified V1a2 cDNA product was also present in gill tissue (Fig. 5). The V2-type receptor transcript, in contrast, was most abundant in the gills, heart, interenal gland, and liver (Fig. 5).

\subsection{Regulation of pro-VT and VT/IT receptor mRNAs in the hypothalamus and gill by salinity}

Acute exposure to hyperosmotic conditions (17ppt or $34 \mathrm{ppt}$ ) for $5 \mathrm{~h}$ or $20 \mathrm{~h}$ altered transcript abundance for pro-VT, and for the VT/IT receptors, in the hypothalamus of juvenile pupfish
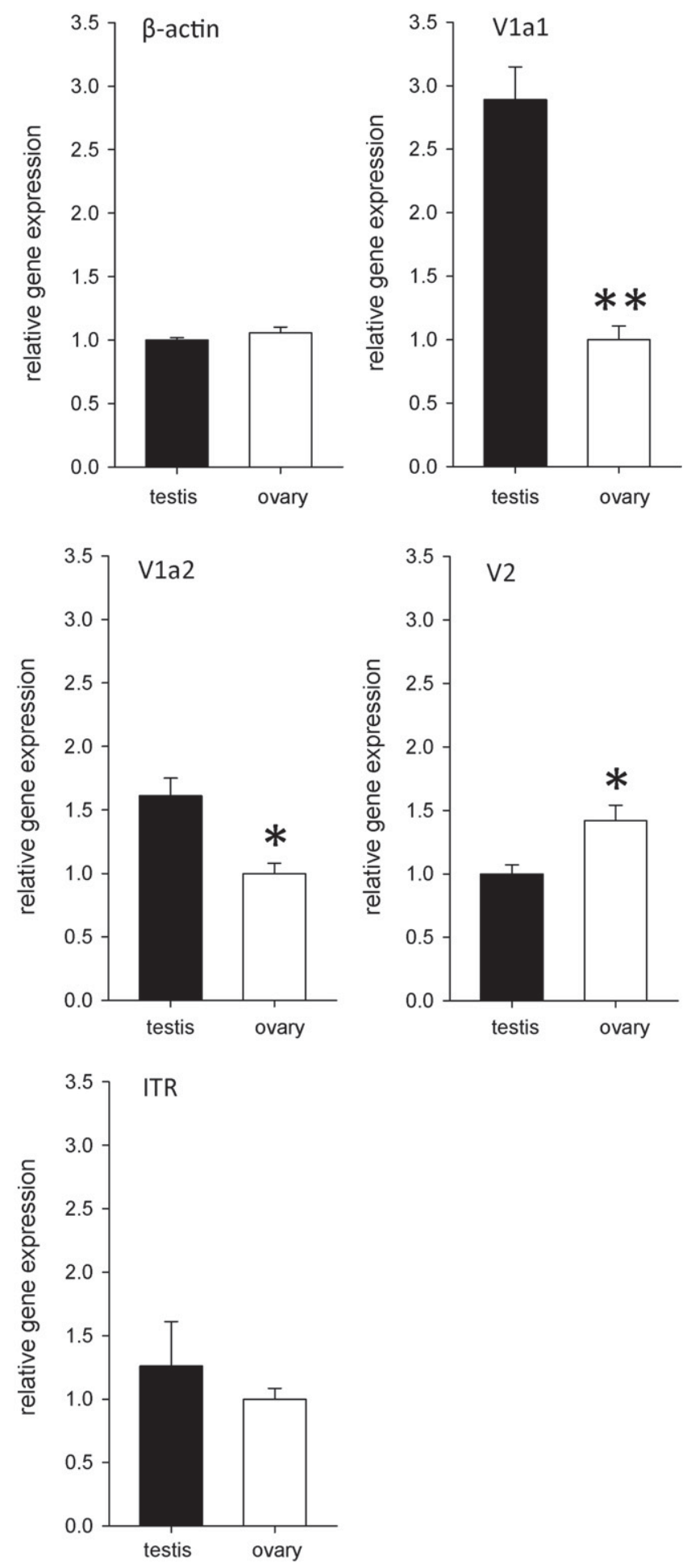

Fig. 6. Semi-quantitative RT-PCR comparison of VT receptor (V1a1, V1a2 and V2) mRNA levels in the gonads of sexually mature male and female pupfish. RT-PCR was run using gene-specific primers and the resulting PCR products visualized on $2 \%$ agarose gels. Relative band intensity was quantified using Image $1.37 \mathrm{v}$ software, and $t$ tests used to compare the expression of each transcript between ovarian and testicular tissues. Asterisks indicate a statistically significant difference between tissues $\left({ }^{*} p<0.05,{ }^{* *} p<0.01\right.$ ). The control gene, $\beta$-actin, showed similar transcript abundance in testicular and ovarian tissues. Transcript levels are expressed as relative values to the mean of the lesser expressed tissue (testis or ovary). All values are plotted as mean \pm SEM. 


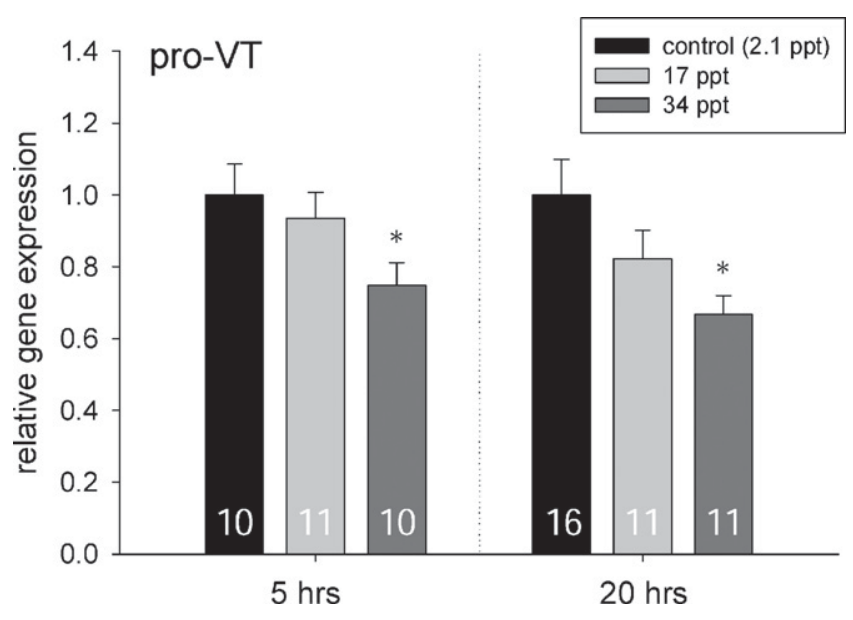

Fig. 7. Acute exposure to elevated salinity results in decreased pro-VT transcript abundance in the hypothalamus. Results are expressed as normalized transcript abundance with respect to $E F-1 \alpha$ transcripts from the same sample. Values are shown as mean \pm SEM, and sample sizes $(n)$ are denoted on each bar. Values significantly different from the control of the same treatment time (Dunnett's tests) are indicated by asterisks $(p<0.05)$.

relative to individuals maintained at natural osmotic conditions $(2.1 \mathrm{ppt})$. Elevated salinity ( $34 \mathrm{ppt})$ caused a reduction in hypothalamic pro-VT mRNA levels at both the $5 \mathrm{~h}$ (Welch ANOVA, $\left.F_{2,18.323}=3.37, p=0.057\right)$ and $20 \mathrm{~h}\left(F_{2,21.679}=4.67, p=0.021\right)$ sampling times (Fig. 7). Transcripts for VT receptors were also altered, with V1a1 mRNA levels increasing by $50 \%$ in the hypothalamus of fish transferred to $34 \mathrm{ppt}$ salinity, relative to control (2.1 ppt) fish (Fig. 8A). This increase in V1a1 mRNA levels was observed at both the $5 \mathrm{~h}\left(F_{2,27}=6.492, p=0.005\right)$ and $20 \mathrm{~h}\left(F_{2,34}=11.194\right.$, $p=0.0002$ ) sampling times. V1a2 mRNA levels also showed a significant increase in pupfish experiencing 34 ppt salinity conditions, although this increase was observed only at the $20 \mathrm{~h}$ sampling time $\left(F_{2,34}=11.386, p=0.0002\right)$ (Fig. 8B). Transcript abundance for the $V 2$ receptor showed a distinctly different pattern of change, with a significant elevation in V2 mRNA levels in pupfish exposed to 17 ppt conditions, but a decline in V2 mRNAs under the 34 ppt conditions $5 \mathrm{~h}$ after commencing the osmotic challenge $\left(F_{2,27}=10.456\right.$, $p=0.0004$ ) (Fig. 8C). These changes in V2 transcript abundance were more consistent at $20 \mathrm{~h}$ of exposure, when fish in both the $17 \mathrm{ppt}$ and $34 \mathrm{ppt}$ treatments displayed reduced hypothalamic V2 mRNA levels $\left(F_{2,34}=15.708, p<0.0001\right)$. Salinity also altered the abundance of transcripts encoding the IT receptor, although these changes were not observed until $20 \mathrm{~h}$ after exposure to elevated salinity, when ITR mRNAs were significantly reduced in the hypothalamus of pupfish from the $17 \mathrm{ppt}$ treatment, but elevated in fish from the $34 \mathrm{ppt}$ exposure group $\left(F_{2,34}=19.634, p<0.0001\right)$ (Fig. 8D).

Acute hypersalinity challenge also affected levels of mRNAs encoding two of the VT receptors - as well as the IT receptor - in the gills, although these changes were distinct from those observed in hypothalamic tissues. In the gills, mRNA levels for the V1a2 receptor increased in pupfish 2- to 2.5-fold within $5 \mathrm{~h}$ of exposure to $17 \mathrm{ppt}$ and $34 \mathrm{ppt}$ salinities, and remained elevated at these levels for at least $20 \mathrm{~h}$ in fish exposed to the $34 \mathrm{ppt}$ conditions (Fig. 9B). Transcripts for the V1a1 receptor declined $40 \%$ in the gill within $5 \mathrm{~h}$ of transfer to $17 \mathrm{ppt}$ water $\left(F_{2,27}=6.204, p=0.006\right)$, but not $34 \mathrm{ppt}$
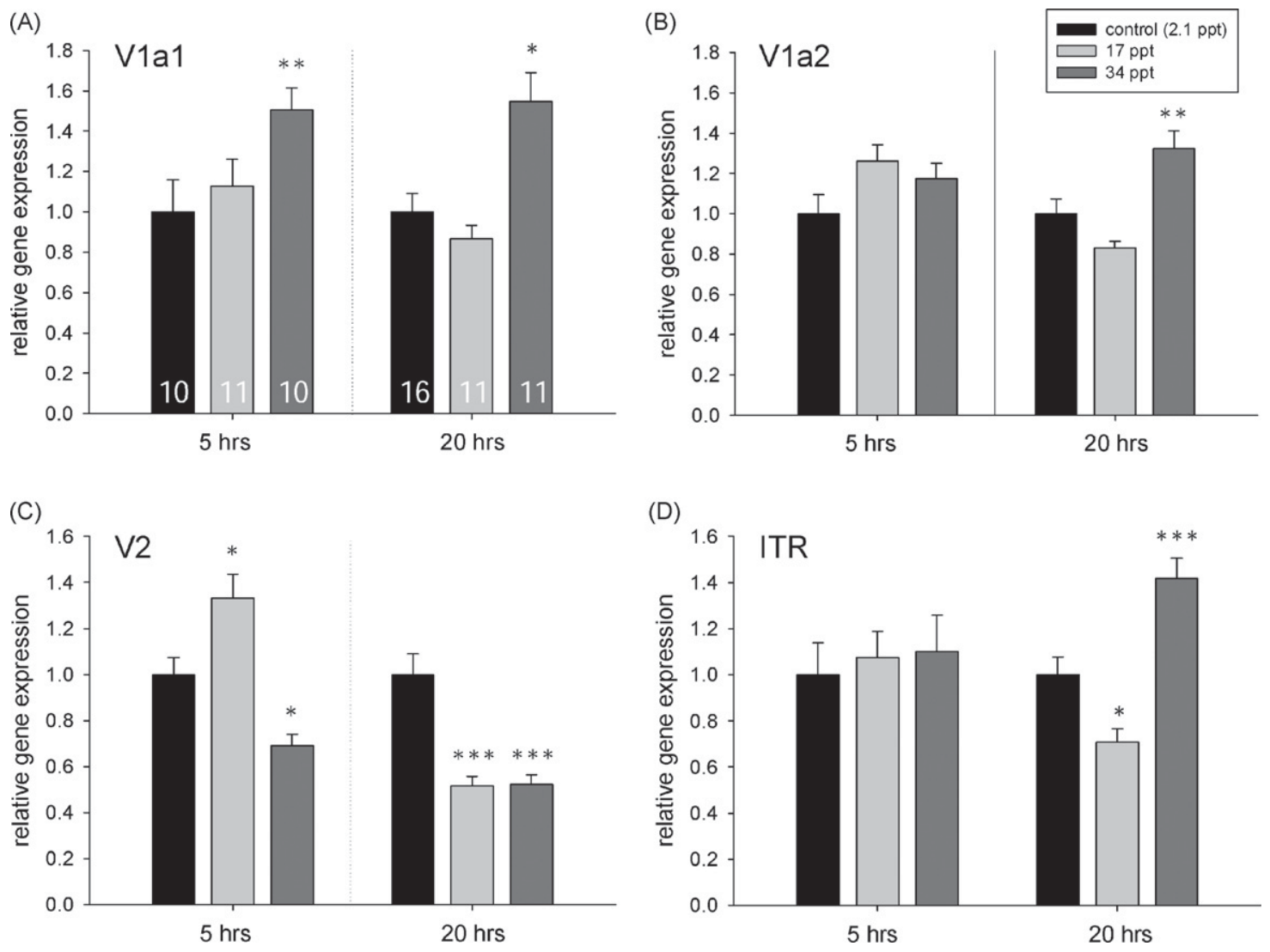

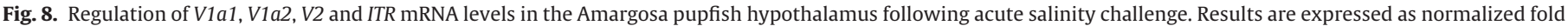

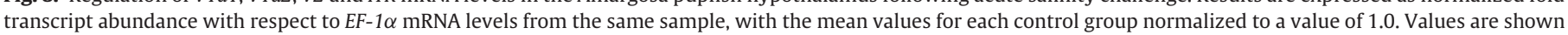

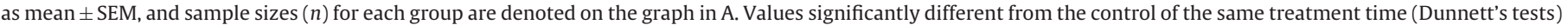
are indicated as follows: ${ }^{*} p<0.05,{ }^{* *} p<0.01,{ }^{* * *} p<0.001$. 

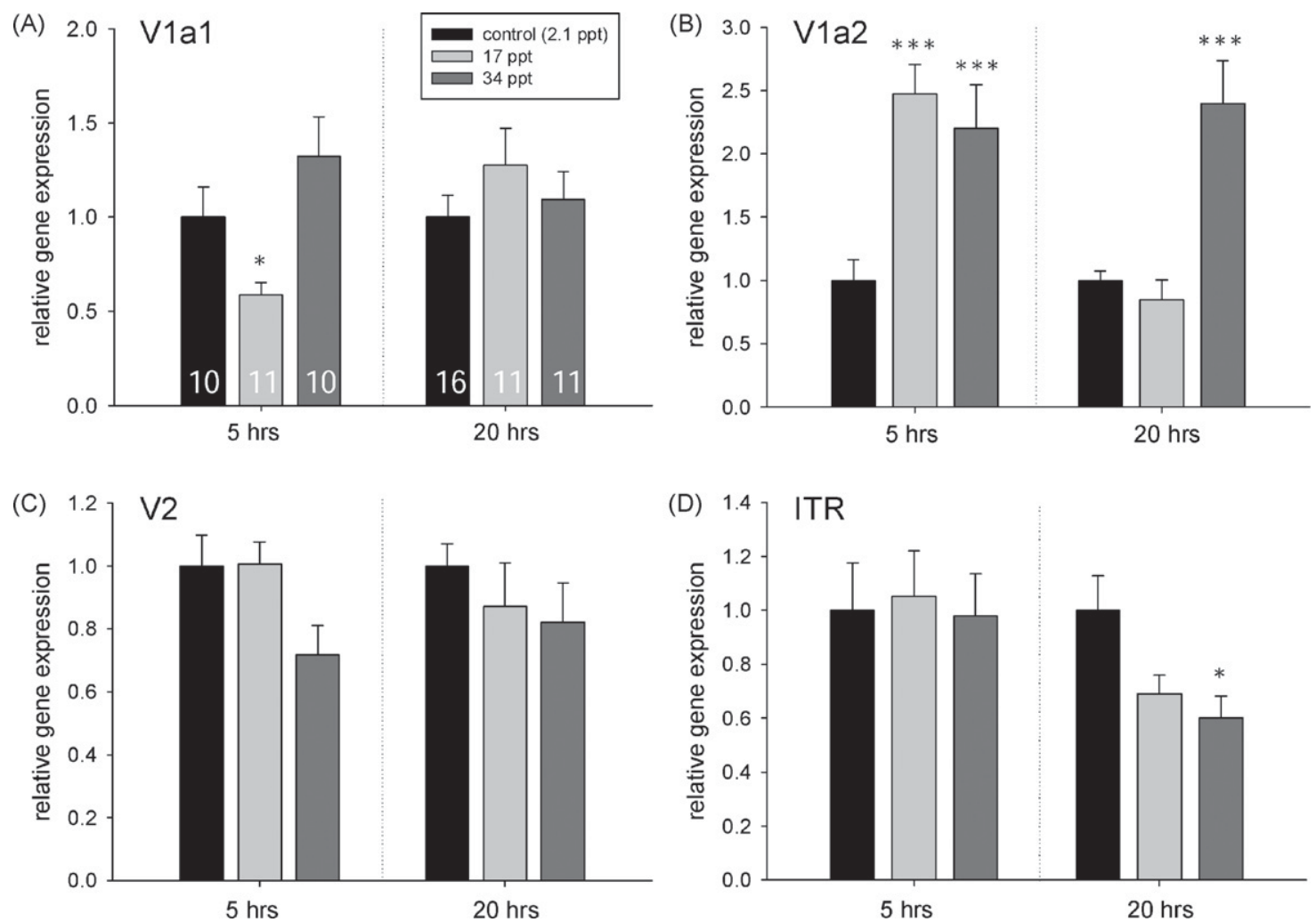

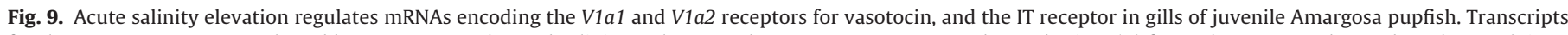
for the $V 2$ receptor were unaltered by exposure to elevated salinity. Values are shown as mean \pm SEM, and sample sizes ( $n$ ) for each group are denoted on the graph in A. Values significantly different from the control of the same treatment time (Dunnett's tests) are indicated as follows: ${ }^{*} p<0.05,{ }^{* *} p<0.01,{ }^{* * *} p<0.001$.

water; however, this decline in V1a1 mRNA levels was not seen at the $20 \mathrm{~h}$ sampling time (Fig. 9A). Transcripts for the IT receptor also decreased in abundance by approximately $40 \%$, although this decline was not apparent until $20 \mathrm{~h}$ of exposure to elevated salinity, and was only statistically significant in pupfish from the $34 \mathrm{ppt}$ treatment $\left(F_{2,34}=3.968, p=0.028\right)$ (Fig. 9D). $V 2$ mRNAs in the gills were unaffected by elevated salinity (Fig. 9C).

\section{Discussion}

In the present study, three full-length cDNAs encoding putative VT receptors were identified and sequenced from a teleost, the Amargosa pupfish. In addition, a single cDNA encoding an IT receptor was isolated and sequenced from the same species. Phylogenetic comparisons of amino acid sequences for these pupfish VT receptors with other vertebrate neurophyophyseal hormone receptors revealed that two of the three pupfish VT receptors belong to the V1a-type clade of VP/VT receptors (V1a1 and V1a2), while the third cDNA (V2) shares greatest amino acid structural similarity with V2-type receptors from mammals and amphibians. To the author's knowledge, this is the first evidence for two distinct V1a-type VT/VP receptor cDNAs in a teleost, as well as the first identification of a V2-type receptor transcript in a ray-finned fish.

Examination of the deduced amino acid sequences for these receptors reveals homology at several amino acid sites identified previously as important for receptor interaction with VT/IT (Hausmann et al., 1996; Archarjee et al., 2004; Ślusarz and Gieidoń, 2006; Cho et al., 2007). All three putative VT receptor cDNAs contain Gln residues in the TM II helix (amino acid 106, as illustrated in the V1a1 deduced protein sequence presented in Fig. 3) and TM III (V1a1 amino acid 129) domains, which generate a hydrophilic cleft in the receptor for VT/IT binding. Similarly, a Lys residue within TM III (V1a1 amino acid 126 in Fig. 3), Thr in TM V (V1a1 amino acid
219), and Phe and Gln residues in TM VI (V1a1 amino acids 303 and 306 , respectively) are conserved across all three VT cDNAs. These four residues produce a lipophilic pocket in the receptor for VT binding (Hausmann et al., 1996). Several other amino acid residues also suggested to be important for VT/IT binding, including a Thr in TM V (V1a1 amino acid 216 in Fig. 3), are also conserved in the putative VT/IT receptor cDNAs identified in pupfish. Although additional biochemical characterization of the three putative VT receptors is still needed, the conservation of these key residues across the three pupfish VT receptors suggests that these cDNAs may encode functional VT receptors.

\subsection{Identification of two pupfish V1a-type VT receptor cDNA paralogs}

Sequence comparison of nucleotide and amino acid structures for the two V1a-type VT receptors (V1a1 and V1a2) from Amargosa pupfish suggests that these receptors are likely paralogs that evolved through a gene duplication event. Genome duplications have occurred repeatedly in many teleost fishes including those of the order Cyprinodontidae, and these duplications, whether occurring at the whole or partial genome level, led Cyprinodontid fishes to have multiple copies of many endocrine-related genes present only singly in mammals (Robinson-Rechavi et al., 2001; Larhammar et al., 2009). Further support for this hypothesis comes from the identification of partial cDNA sequences for a homologous pair of V1a-type receptors in the closely related Atlantic pupfish (Cyprinodon variegatus) (V1a1, Genbank accession no. GU120189; V1a2, GU120190) (S.C. Lema, current study, results not shown). Whether two V1a-type receptors have evolved more broadly in teleosts remains to be determined, but given the broad patterns of gene duplications seen in fish (Larhammar et al., 2009), and the presence of two gene sequences for homologous V1a-type receptors 
in the Tetraodontid fish Takifugu rubripes (GenBank accession nos. AY027886 and AY027887), it seems likely that similar V1a-type receptor paralogs may be found in many teleost taxa.

While the functional roles of the V1a1 and V1a2 receptors remains to be determined, RT-PCR revealed that the two pupfish V1a-type VT receptors have distinct mRNA expression patterns, with V1a1 mRNAs most abundant in the midbrain, cerebellum, pituitary gland and testis, and V1a2 transcripts common in midbrain, cerebellum, heart and muscle. Although RT-PCR expression patterns cannot pinpoint specific roles for either receptor, the distribution patterns do suggest functional differentiation. For instance, V1a1 transcripts were abundant in the pituitary gland of both male and female pupfish, suggesting a possible role for this receptor in regulating negative feedback on VT secretion, or possibly as a modulator of VT-induced ACTH release and activation of the HPA axis (Baker et al., 1996; Engelmann et al., 2004). Supporting this idea, Pierson et al. (1996) demonstrated in previous work that VT stimulation of pituitary ACTH release in the rainbow trout occurred via a V1-type receptor-mediated pathway. Meanwhile, in the gonads, the dissimilar transcript distribution patterns suggest that the V1a1 and V1a2 receptors may have distinct functions in reproduction. Recently, VT peptide was localized to the gonads of the catfish Heteropneustes fossilis (Singh and Joy, 2008). Gonadal VT levels in this species showed a distinct sex difference, with higher VT in the ovary than the testis, but with both tissues showing changes in VT levels over the reproductive season (Singh and Joy, 2008). Singh and Joy (2009) subsequently found that VT regulates $17 \beta$-estradiol production by the catfish ovary, with VT either increasing or decreasing $17 \beta$-estradiol levels depending on the stage of the reproductive cycle. The sex difference in gonadal V1a1 transcript abundance seen here between adult male and female pupfish therefore suggests that the V1a1 receptor may play a role in regulating sex-specific effects of VT on the gonad.

In the central nervous system, V1a1 and V1a2 transcripts were abundant in the midbrain of male and female pupfish, suggesting a role for these receptors in mediating neural responses to VT. Neural expression of VT has been shown to be associated with social status in several fish species (Grober et al., 2002; Larson et al., 2006), and there is evidence that neural VT expression may correlate with species- or population-level variation in sociosexual behaviors (Lema and Nevitt, 2004a; Lema, 2006; Dewan et al., 2008). Previously, V1a-type receptor antagonists (e.g., Manning compound) have been shown to induce opposing effects to exogenous VT for social behaviors including aggression and courtship (Semsar and Godwin, 2004; Santangelo and Bass, 2006; see also Semsar et al., 2001; Lema and Nevitt, 2004b). Moreover, sex change in the bluehead wrasse (Thalassoma bifasciatum) has been shown to be induced by primary influences of the social environment on neural VT pathways (Semsar and Godwin, 2003). Future studies that examine the roles of $V 1 a 1$ and $V 1 a 2$ receptors in mediating behavioral transitions accompanying changes in social status or gonadal sex hold great promise for providing new insights into VT's regulation of behavior.

\subsection{Identification of a V2-type receptor cDNA in pupfish}

Results presented here provide the first description of a V2type receptor cDNA in teleost fish. This full-length V2 cDNA, with an open reading frame encoding a deduced protein of 497 amino acids, showed greatest amino acid identity to V2-type receptors from tetrapods (Fig. 4). Additional evidence for the presence of V2-type receptors in other teleost fish comes from partial sequences for homologous V2 cDNAs obtained from the closely related Atlantic pupfish (Cyprinodon variegatus) (GenBank accession no. GU120191), and from the more distantly-related Perciform fish, Stegastes partitus (GenBank accession no. GU120192) (S.C. Lema, current study, results not shown).

Even though the deduced protein encoded by the pupfish V2 cDNA showed the greatest sequence similarity to V2-type receptors from mammals and amphibians, the similarity was unexpectedly low (i.e., $47 \%$ identity to the lungfish V2-type receptor) (Table 3) due to the presence of an elongated intracellular loop III region (ICL III) in the deduced V2 receptor's structure (Fig. 3). The presence of this elongated ICL III loop was confirmed by full-length PCR and sequencing of both the V2 cDNA and gene using primers designed to the $5^{\prime}$ and $3^{\prime}$ UTRs.

In V2-type receptors (Böselt et al., 2009) and, more generally, rhodopsin-like G-coupled receptors (Probst et al., 1992), the ICL III loop of the receptor is the region showing least conservation in residue composition and length. In mammalian V2-type receptors, the ICL III loop has been shown to be critical for receptor signal transduction (Liu and Wess, 1996). The binding of VP to the mammalian V2 receptor induces transformational changes in the ICL III loop, which interacts with G-coupled protein $\mathrm{G} \alpha \mathrm{S}$ and other intracellular proteins (e.g., gC1qR) to generate an intracellular signaling cascade (Erlenbach and Wess, 1998; Bellot et al., 2009). The elongated ICL III loop of the pupfish V2 receptor might therefore indicate evolutionary divergence in the receptor's intracellular transduction mechanism.

Additional work is needed to determine whether the protein encoded by this newly identified V2 cDNA constitutes a functional receptor or represents a pseudogene or fusion gene. If this cDNA does not encode a functional receptor, the transcript might be playing a regulatory role in post-transcriptional intracellular processing of a similarly structured V2-type receptor in the Amargosa pupfish. It is interesting to note, however, that RT-PCR revealed a high abundance of the V2 transcript in the gills and kidney, which suggests a role for this receptor in maintaining hydromineral balance. Providing further support for this idea, results from the acute salinity challenge demonstrated that V2 transcripts were regulated in the hypothalamus and gill by hyperosmotic conditions (results discussed below).

Whether or not the V2-type cDNA encodes a functional receptor, its identification provides evidence that V2-type receptors evolved prior to the divergence of Actinopterygii fishes from the modern tetrapod lineage. The recent discovery and characterization of a V2-type receptor cDNA in the Sarcopterygian lungfish, Protopterus annectens, lends additional support for this early-origin hypothesis (Konno et al., 2009). Taken together, the presence of V2-type receptor cDNAs in these fishes indicate that V2-type VT/VP receptors evolved earlier in vertebrate evolution than previously thought, and it should be expected that similar V2-type receptor genes will be identified in other Actinopterygian fishes.

\subsection{Response of pro-VT and VT/IT receptors to hyperosmotic challenge}

Amargosa pupfish, and other members of the genus Cyprinodon, are euryhaline (Hillyard, 1981), and some taxa within the Death Valley clade of pupfishes can withstand salinities up to $105 \mathrm{ppt}$ (Naiman et al., 1976). This extreme salinity tolerance has allowed Cyprinodon pupfishes to occupy a range of habitats - from coastal salt marshes to desert streams - which are outside the physiological scope of most other teleosts. It has not yet been examined, however, what role neurohypophyseal neuropeptides play in the regulation of hydromineral balance in pupfish.

In this study, the transfer of juvenile Amargosa pupfish from low salinity (2.1 ppt) to hypersaline ( $34 \mathrm{ppt}$ ) conditions caused a significant reduction in hypothalamic pro-VT transcript abundance. This decrease was seen in pupfish after $5 \mathrm{~h}$ and $20 \mathrm{~h}$ of exposure to 34 ppt (Fig. 7). In teleost fishes, it is well established that changes 
in environmental salinity alter the secretion of VT, which then regulates hydromineral permeability at the level of the kidney, gills and intestine (reviewed by Warne, 2002). In freshwater rainbow trout (Oncorhynchus mykiss), hyperosmotic stress has been shown to result in increased plasma VT levels (Kulczykowska, 1997, 2001). Freshwater-acclimated medaka (Oryzias latipes) transferred to seawater showed reduced pituitary VT content (Haruta et al., 1991), while VT content of the pituitary has been shown to increase in seawater-acclimated medaka and flounder (Platichthys flesus) transferred to freshwater (Warne et al., 2000; Haruta et al., 1991).

Corresponding to these changes in pituitary and plasma VT levels following osmotic challenge, hypothalamic VT expression has also been shown to respond to altered environmental salinities. In rainbow trout, the number of VT-immunoreactive (VT-ir) neurons in the magnocellular region of the preoptic area decreased following transfer of fish from freshwater to seawater (Haruta et al., 1991). Hyodo and Urano (1991) demonstrated that pro-VT mRNA in situ hybridization signal in hypothalamic magnocellular neurons of rainbow trout declined within one day of transfer from freshwater to $80 \%$ seawater. Taken as a whole, these results indicate that acute hyperosmotic challenge increases plasma VT levels by stimulating secretion of VT peptide from the neurohypophysis, and that hyposomotic conditions have the opposite effect (reviewed by Warne, 2002). From the findings of the current study and those of previous work (Hyodo and Urano, 1991; Haruta et al., 1991), it appears that the acute changes in pituitary VT secretion are often paralleled by decreases in magnocellular pro-VT mRNA levels, possibly resulting from an increase in pro-VT mRNA translation.

There are a few studies, however, that suggest the response of preoptic pro-VT mRNAs to hypersaline challenge may vary among species or across testing conditions. For instance, flounder (Platichthys flesus) transferred from freshwater to seawater showed the expected increase in plasma VT and decrease in pituitary VT protein levels within $8 \mathrm{~h}$, but also had elevated, rather than reduced, hypothalamic pro-VT mRNA levels $4 \mathrm{~h}$ and $8 \mathrm{~h}$ after transfer (Warne et al., 2005). Similarly, hypothalamic pro-VT mRNA levels were found to decrease in stenohaline pufferfish (Takifugu rubripes) one day after transfer to hyposmotic conditions (Motohashi et al., 2009). Whether the differential responses of hypothalamic pro-VT transcript abundance to osmotic challenge indicate species differences in the ability to acclimate to rapid salinity changes, result from variations in experimental design and testing conditions, or demonstrate differential regulation of mRNA transcriptional/translational processes is unclear. Pro-VT transcripts in hypothalamic parvocellular neurons of the teleost preoptic area are also known to be stress-responsive (Gilchriest et al., 2000), and inadvertent stresses associated with transfer of fish from one salinity to another might have altered hypothalamic pro-VT mRNA levels compared to those expected under osmotic challenge alone. In any case, magnocelllular VT-ir neuron number was observed previously to be reduced in Amargosa pupfish raised in freshwater $(0.4 \mathrm{ppt})$ conditions compared to more saline ( $3 \mathrm{ppt}$ ) conditions (Lema, 2006), and when combined with the changes in pro-VT transcript abundance observed in the present study, these findings indicate a role for hypothalamic pro-VT expression in regulating hydromineral balance in pupfish.

Results from the acute osmotic challenge conducted here also revealed that mRNAs encoding pupfish VT/IT receptors are differentially regulated in hypothalamic and gill tissues, suggesting that the receptors have distinct functional roles in mediating the physiological and behavioral responses to osmotic stress. Few studies have examined changes in teleost VT receptor mRNAs in response to salinity challenge. In studies using the flounder Platichthys flesus, chronically acclimated seawater and freshwater fish showed no difference in either gill or kidney VT receptor transcript abundance (Warne et al., 2005; Balment et al., 2006). However, transfer of seawater-acclimated flounder to freshwater for $24 \mathrm{~h}$ reduced both gill and kidney VT receptor transcript abundance (Balment et al., 2006). The receptor examined in these studies with flounder was a V1a-type receptor, and the findings of Balment and coworkers (2006) are consistent with the changes in V1a2 receptor mRNA levels seen here with pupfish. This result, however, contrasts with that in olive flounder (Paralichthys olivaceus), where transfer of seawater-acclimated ( $35 \mathrm{psu}$ ) fish to decreased salinities for $48 \mathrm{~h}$ resulted in increased V1a-type receptor mRNA levels in gill (and intestine) at salinities of $4,8.75$ and $17.5 \mathrm{psu}$, and increased VT receptor mRNA in the kidney at 0 psu (An et al., 2008b).

\subsection{Conclusions}

Results presented here provide the first evidence for two V1a-type receptor paralogs and a V2-type receptor in an Actinopterygian fish. This research also shows that these three VT receptors exhibit distinct tissue patterns of expression and are differentially regulated in the hypothalamus and gill in response to hyperosmotic challenge. Given that VT has been found to regulate stress responses (Baker et al., 1996; Gilchriest et al., 2000) and social behaviors (for reviews, see Foran and Bass, 1999; Goodson and Bass, 2001) in teleost fishes - in addition to its well-established role in maintaining hydromineral balance - future research into the expressional regulation and function these three VT receptors promises to provide new insights into the diverse physiological and behavioral roles of VT in fish.

\section{Acknowledgements}

This research was supported by a Cahill Award from the University of North Carolina, Wilmington. All procedures in this research followed the guidelines outlined by the Animal Care and Use Committee of the University of North Carolina, Wilmington (Protocol \#A0809-007). Collection of pupfish was conducted with permission of the California Department of Fish and Game (801129-01) and the US Bureau of Land Management (CA-063.50). The author thanks Dr. Kristin Hardy, for comments that greatly improved the quality of this manuscript.

\section{References}

Amer, S., Brown, J.A., 1995. Glomerular actions of arginine vasotocin in the in situ perfused trout kidney. Am. J. Physiol. Regul. Integr. Comp. Physiol. 269, 775-780.

An, K.W., Kim, N.N., Choi, C.Y., 2008a. Cloning and expression of aquaporin 1 and arginine vasotocin receptor mRNA from the black porgy, Acanthopagrus schlegeli: effect of freshwater acclimation. Fish Physiol. Biochem. 34, 185-194.

An, K.W., Shin, H.S., An, M.I., Jo, P.G., Choi, Y.K., Choi, C.Y., 2008b. Physiological response and expression of arginine vasotocin receptor, prolactin and prolactin receptor mRNA in olive flounder Paralichthys olivaceus during osmotic stress. Mar. Fresh. Behav. Physiol. 41, 191-203.

Archarjee, S., Do-Rego, J.L., Oh, D.Y., Ahn, R.S., Choe, H., Vaudry, H., Kim, K., Seong J.Y., Kwon, H.B., 2004. Identification of amino acid residues that direct differential ligand selectivity of mammalian and non-mammian V1a type receptors for arginine vasopressin and vasotocin: Insights into molecular coevolution of V1a type receptors and their ligands. J. Biol. Chem. 279, 54445-54453.

Avella, M., Pärt, P., Ehrenfeld, J., 1999. Regulation of $\mathrm{Cl}^{-}$secretion in seawater fish (Dicentrarchus labrax) gill respiratory cells in primary culture. J. Physiol. 516, 353-363.

Baeyens, D.A., Cornett, L.E., 2006. The cloned avian neurohypophysial hormone receptors. Comp. Biochem. Physiol. B, 12-19.

Baker, B.I., Bird, D.J., Buckingham, J.C., 1996. In the trout, CRH and AVT syngerize to stimulate ACTH release. Reg. Pept. 67, 207-210.

Balment, R.J., Lu, W., Weybourne, E., Warne, J.M., 2006. Arginine vasotocin a key hormone in fish physiology and behaviour: a review with insights from mammalian models. Gen. Comp. Endocrinol. 147, 9-16. 
Balment, R.J., Warne, J.M., Tierney, M., Hazon, N., 1993. Arginine vasotocin and fish osmoregulation. Fish Physiol. Biochem. 11, 189-194.

Barberis, C., Mouillac, B., Durroux, T., 1998. Structural bases of vasopressin/oxytocin receptor function. J. Endocrinol. 156, 223-229.

Bellot, G., Granier, S., Bourguet, W., Seyer, R., Rahmeh, R., Mouillac, B., Pascal, R., Mendre, C., Déméné, H., 2009. Structure of the third intracellular loop of the vasopressin V2 receptor and conformational changes upon binding to $\mathrm{gC} 1 \mathrm{qR}$. J. Mol. Biol. 388, 491-507.

Böselt, I, Römpler, H., Hermsdorf, T., Thor, D., Busch, W., Schulz, A., Schöneberg, T., 2009. Involvement of the V2 vasopressin receptor in adaptation to limited water supply. PLoS One 4, e5573. doi:10.1371/journal.pone.0005573.

Cho, H.J., Acharjee, S., Moon, M.J., Oh, D.Y., Vaudry, H., Kwon, H.B., Seong, J.Y., 2007. Molecular evolution of neuropeptide receptors with regard to maintaining high affinity to their authentic ligands. Gen. Comp. Endocrinol. 153, 98-107.

Conklin, D.J., Smith, M.P., Olson, K.R., 1999. Pharmacological characterization of arginine vasotocin vascular smooth muscle receptors in the trout (Oncorhynchus mykiss) in vitro. Gen. Comp. Endocrinol. 114, 36-46.

Cornett, L.E., Kirby, J.D., Vizcarra, J.A., Ellison, J.C., thrash, J., Mayeux, P.R., Crew, M.D., Jones, S.M., Ali, N., Baeyens, D.A., 2003. Molecular cloning and functional characterization of a vasotocin receptor subtype expressed in the pituitary gland of the domestic chicken (Gallus domesticus): avian homolog of the mammalian V1b-vasopressin receptor. Regul. Pept. 110, 231-239.

Darlison, M.G., Richter, D., 1999. Multiple genes for neuropeptides and their receptors: co-evolution and physiology. Trends Neurosci. 22, 81-88.

Dewan, A.K., Maruska, K.P., Tricias, T.C., 2008. Arginine vasotocin neuronal populations among congeneric territorial and shoaling reef butterflyfishes: species, sex and reproductive season comparisons. J. Neuroendocrinol. 20, 1382-1394.

Engelmann, M., Landgraf, R., Wotjak, C.T., 2004. The hypothalamic-neurohypophysial system regulates the hypothalamic-pituitary-adrenal axis under stress: an old concept revisited. Front. Neuroendocrinol. 25, 132-149.

Erlenbach, I., Wess, J., 1998. Molecular basis of V2 vasopressin receptor/Gs coupling selectivity. J. Biol. Chem. 273, 26549-26558.

Foran, C.M., Bass, A.H., 1999. Preoptic GnRH and AVT: axes for sexual plasticity in teleost fish. Gen. Comp. Endocrinol. 116, 141-152.

Gilchriest, B.J., Tipping, D.R., Hake, L., Levy, A., Baker, B.I., 2000. The effects of acute and chronic stresses on vasotocin gene transcripts in the brain of the rainbow trout (Oncorhunchus mykiss). J. Neuroendocrinol. 12, 795-801.

Goodson, J.L., Bass, A.H., 2001. Social behaviour functions and related anatomical characteristics of vasotocin/vasopressin systems in vertebrates. Brain Res. Rev. $35,246-265$.

Grober, M.S., George, A.A., Watkins, K.K., Carneiro, L.A., Oliveira, R.F., 2002. Forebrain AVT and courtship in a fish with male alternative reproductive tactics. Brain Res. Bull. 57, 423-425.

Guibbolini, M.E., Lahlou, B., 1987. Neurohypophyseal peptide inhibition of adenylate cyclase activity in fish gills: effects of environmental salinity. FEBS Lett. 220, 98-102.

Guibbolini, M.E., Henderson, I.W., Mosley, W., Lahlou, B., 1988. Arginine vasotocin binding to isolated branchial cells of the eel: effect of salinity. J. Mol. Endocrinol. $1,125-130$.

Guibbolini, M.E., Lahlou, B., 1990. Evidence for presence of a new type of neurohypophysial hormone receptor in fish gill epithelium. Am. J. Physiol. Integ. Comp. Physiol. 258, 3-9.

Guibbolini, M.E., Lahlou, B., 1992. G G $_{\text {i }}$ protein mediates adenylate cyclase inhibition by neurohypophyseal hormones in fish gill. Peptides 13, 865-871.

Guibbolini, M.E., Pierson, P.M., Lahlou, B., 2000. Neurohypophysial hormone receptors and second messengers in trout hepatocytes. J. Endocrinol. 167, 137-144.

Guibbolini, M.E., Avella, M., 2003. Neurohypophysial hormone regulation of $\mathrm{Cl}^{-}$ secretion: physiological evidence for V1-type receptors in sea bass gill respiratory cells in culture. J. Endocrinol. 176, 111-119.

Haruta, K., Yamashita, T., Kawashima, S., 1991. Changes in arginine vasotocin content in the pituitary of the medaka (Oryzias latipes) during osmotic stress. Gen. Comp. Endocrinol. 83, 327-336.

Hasunuma, I., Sakai, T., Nakada, T., Toyoda, F., Namiki, H., Kikuyama, S., 2007. Molecular cloning of three types of arginine vasotocin receptor in the newt, Cynops pyrrhogaster. Gen. Comp. Endocrinol. 151, 252-258.

Hausmann, H., Richters, A., Kreienkamp, H.-J., Meyerhof, W., Mattes, H., Lederis, K., Zwiers, H., Richter, D., 1996. Mutational analysis and molecular modeling of the nonapeptide hormone binding domains of the $\left[\mathrm{Arg}^{8}\right]$ vasotocin receptor. Proc. Natl. Acad. Sci. U.S.A. 93, 6907-6912.

Hausmann, H., Meyerhof, W., Zwiers, H., Lederis, K., Richter, D., 1995. Teleost isotocin receptor: structure, functional expression, mRNA distribution and phylogeny. FEBS Lett. 370, 227-230.

Hillyard, S.D., 1981. Energy metabolism and osmoregulation in desert fishes. In: Naiman, R.J., Soltz, D.L. (Eds.), Fishes in North American Deserts. John Wiley and Sons, New York, pp. 385-409.

Hyodo, S., Urano, A., 1991. Changes in expression of provasotocin and proisotocin genes during adaptation to hyper- and hypo-osmotic environments in rainbow trout. J. Comp. Physiol. B 161, 549-556.

Insel, T.R., Wang, Z.-X., Ferris, C.F., 1994. Patterns of brain vasopressin receptor distribution associated with social organization in microtine rodents. J. Neurosci. 14, 5381-5392.

Jones, D.T., 2007. Improving the accuracy of transmembrane protein topology prediction using evolutionary information. Bioinformatics $23,538-544$

Jones, D.T., Taylor, W.R., Thornton, J.M., 1994. A model recognition approach to the prediction of all-helical membrane protein structure and topology. Biochem. 33, 3038-3049.
Jurkevich, A., Berghman, L.R., Cornett, L.E., Kuenzel, W.J., 2005. Characterization and immunohistochemical visualization of the vasotocin VT2 receptor in the pituitary gland of the chicken, Gallus gallus. Gen. Comp. Endocrinol. 143, 82-91.

Kawada, T Sekiguchi, T, Itoh, Y Ogasawara, M., Satake, H, 2008 Characterization of a novel vasopressin/oxytocin superfamily peptide and its receptor from an ascidian, Ciona intestinalis. Peptides 29, 1672-1678.

Konno, N., Hyodo, S., Yamaguchi, Y., Kaiya, H., Miyazato, M., Matsuda, K., Uchiyama, M., 2009. African lungfish, Protopterus annectens, possess an arginine vasotocin receptor homologous to the tetrapod V2-type receptor. J. Exp. Biol. 212, 2183-2193.

Kulczykowska, E., 1997. Response of circulating arginine vasotocin and isotocin to rapid osmotic challenge in rainbow trout. Comp. Biochem. Physiol. A 118, 773-778.

Kulczykowska, E., 2001. Responses of circulating arginine vasotocin, isotocin, and melatonin to osmotic and disturbance stress in rainbow trout (Oncorhynchus mykiss). Fish Physiol. Biochem. 24, 201-206.

Kyte, J., Doolittle, R.F., 1982. A simple method for displaying the hydropathic character of a protein. J. Mol. Biol. 157, 105-132.

Larhammar, D., Sundstrom, G., Dreborg, S., Daza, D.O., Larsson, T.A., 2009. Major genomic events and their consequences for vertebrate evolution and endocrinology. Ann. New York Acad. Sci. 1163, 201-208.

Larkin, M.A., Blackshields, G., Brown, N.P., Chenna, R., McGettigan, P.A., McWilliam, H., Valentin, F., Wallace, I.M., Wilm, A., Lopez, R., Thompson, J.D., Gibson, T.J., Higgins, D.G., 2007. Clustal $W$ and Clustal X version 2.0. Bioinformatics 23, 2947-2948.

Larson, E.T., O’Malley, D.M., Melloni Jr., R.H., 2006. Aggression and vasotocin are associated with dominant-subordinate relationships in zebrafish. Behav. Brain Res. 167, 94-102.

Lema, S.C., Nevitt, G.A., 2004a. Exogenous vasotocin alters aggression during agonistic exchanges in male Amargosa River pupfish (Cyprinodon nevadensis amargosae). Horm. Behav. 46, 628-637.

Lema, S.C., Nevitt, G.A., 2004b. Variation in vasotocin immunoreactivity in the brain of recently isolated populations of a Death Valley pupfish, Cyprinodon nevadensis. Gen. Comp. Endocrinol. 135, 300-309.

Lema, S.C., 2006. Population divergence in plasticity of the AVT system and its association with aggressive behaviors in a Death Valley pupfish. Horm. Behav. 50, 183-193.

Lema, S.C., Gardner, N.M., Wagstaff, L. Diurnal expression of mRNAs encoding arginine vasotocin, isotocin, and their receptors in the brain relative to daily rhythms of aggression and courtship in Amargosa pupfish. submitted for publication.

Liu, J., Wess, J., 1996. Different single receptor domains determine the distinct G protein coupling profiles of members of the vasopressin receptor family. J. Biol. Chem. 271, 8772-8778.

Mahlmann, S., Meyerhof, W., Hausmann, H., Heierhorst, J., Schönrock, C., Zwiers, H., Lederis, K., Richter, D., 1994. Structure, function, and phylogeny of $\left[\mathrm{Arg}^{8}\right]$ vasotocin receptors from telesot fish and toad. Proc. Natl. Acad. Sci. U.S.A. 91, 1342-1345.

Moons, L., Cambré, M., Batten, T.F.C., Vandesande, F., 1989. Autoradiographic localization of binding sites for vasotocin in the brain and pituitary of the sea bass (Dicentrarchus labrax). Neurosci. Lett. 100, 11-16.

Motohashi, E., Hasegawa, S., Mishiro, K., Ando, H., 2009. Osmoregulatory responses of expression of vasotocin, isotocin, prolactin and growth hormone genes following hypoosmotic challenge in a stenohaline marine teleost, tiger puffer (Takifugu rubripes). Comp. Biochem. Physiol. A 154, 353-359.

Naiman, R.J., Gerking, S.D., Stuart, R.E., 1976. Osmoregulation in the Death Valley pupfish Cyprinodon milleri (Pisces: Cyprinodontidae). Copeia 1976, 807-810.

Palczewski, K., Kumasaka, T., Hori, T., Behnke, C.A., Motoshima, H., Fox, B.A., Trong, I.L., Teller, D.C., Okada, T., Stenkamp, R.E., Yamamoto, M., Miyano, M., 2000. Crystal structure of rhodopsin: a G protein-coupled receptor. Science 289, 739-745.

Perrott, M.N., Sainsbury, R.J., Balment, R.J., 1993. Peptide hormone stimulated second messenger production in the teleostean nephron. Gen. Comp. Endocrinol. 89, 387-395.

Pierson, P.M., Guibbolini, M.E., Lahlou, B., 1996. A V V $_{1}$ type receptor for mediating the neurohypophyseal hormone-induced ACTH release in trout pituitary. J. Endocrinol. 149, 109-115.

Probst, W.C., Snyder, L.A., Schuster, D.I., Borsius, J., Sealfon, S.C., 1992. Sequence alignment of the G-protein coupled receptor superfamily. DNA Cell Biol. 11, $1-20$.

Robinson-Rechavi, M., Marchand, O., Escriva, H., Bardet, P.-L., Zelus, D., Hughes, S., Laudet, V., 2001. Euteleost fish genomes are characterized by expansion of gene families. Genome Res. 11, 781-788.

Saitou, N., Nei, M., 1987. The neighbor-joining method: A new method for reconstructing phylogenetic trees. Mol. Biol. Evol. 4, 406-425.

Santangelo, N., Bass, A.H., 2006. New insights into neuropeptide modulation of aggression: field studies of arginine vasotocin in a territorial tropical damselfish. Proc. R. Soc. B 273, 3085-3092.

Semsar, K., Kandel, F.L.M., Godwin, J., 2001. Manipulations of the AVT system shift social status and related courtship and aggressive behavior in the bluehead wrasse. Horm. Behav. 40, 21-31.

Semsar, K., Godwin, J., 2004. Multiple mechanisms of phenotype development in the bluehead wrasse. Horm. Behav. 45, 345-353.

Semsar, K., Godwin, J., 2003. Social influences on the arginine vasotocin system are independent of gonads in sex-changing fish. J. Neurosci. 23, 4386-4393.

Singh, V., Joy, K.P., 2009. Relative in vitro seasonal effects of vasotocin and isotocin on ovarian steroid hormone levels in the catfish Heteropneustes fossilis. Gen. Comp. Endocrinol. 162, 257-264. 
Singh, V., Joy, K.P., 2008. Immunocytochemical localization HPLC characterization, and seasonal dynamics of vasotocin in the brain, blood plasma and gonads of the catfish Heteropneustes fossilis. Gen. Comp. Endocrinol. 159, 214-225.

Ślusarz, M.J., Gieidoń, A., Ślusarz, R., Ciarkowski, J., 2006. Analysis of interactions responsible for vasopressin binding to human neurohypophyseal hormone receptors-molecular dynamics study of the activated receptor-vasopressin- $G_{\alpha}$ systems. J. Peptide Sci. 12, 180-189.

Soltz, D.L., 1974. Variation in life history and social organization of some populations of Nevada pupfish, Cyprinodon nevadensis. Ph.D. Thesis. Univ. of California, Los Angeles.

Stafflinger, E., Hansen, K.K., Hauser, F., Schneider, M., Cazzamali, G., Williamson, M., Grimmelikhuijzen, C.J.P., 2008. Cloning and identification of an oxytocin/vasopressin-like receptor and its ligand from insects. Proc. Natl. Acad. Sci. U.S.A. 105, 3262-3267.

Tamura, K., Dudley, J., Nei, M., Kumar, S., 2007. MEGA4: molecular evolutionary genetics analysis (MEGA) software version 4.0. Mol. Biol. Evol. 24, 1596-1599.

Tan, F.L., Lolait, S.J., Brownstein, M.J., Saito, N., MacLeod, V., Baeyens, D.A., Mayeux, P.R., Jones, S.M., Cornett, L.E., 2000. Molecular cloning and functional characterization of a vasotocin receptor subtype that is expressed in the shell gland and brain of the domestic chicken. Biol. Reprod. 62, 8-15.

Thibonner, M., Auzan, C., Madhun, Z., Wilkins, P., Berti-Mattera, L., Clauser, E., 1994. Molecular cloning, sequencing, and functional expression of a cDNA encoding the human V1a vasopressin receptor. J. Biol. Chem. 269, 3304-3310.
Wargent, E.T., Burgessm, W.J., Laycock, J.F., Balment, R.J., 1999. Separate receptors mediate oxytocin and vasopressin stimulation of cAMP in rat inner medullary collecting duct cells. Exp. Physiol. 84, 17-25.

Warne, J.M., Hyodo, S., Harding, K., Balment, R.J., 2000. Cloning of pro-vasotocin and pro-isotocin cDNAs from the flounder Platichthys flesus; levels of hypothalamic mRNA following acute osmotic challenge. Gen. Comp. Endocrinol. 119, 77-84.

Warne, J.M., 2001. Cloning and characterization of an arginine vasotocin receptor from the euryhaline flounder Platichthys flesus. Gen. Comp. Endocrinol. 122, 312-319.

Warne, J.M., Harding, K.E., Balment, R.J., 2002. Neurohypophysial hormones and renal function in fish and mammals. Comp. Biochem. Physiol. B 132, 231-237.

Warne, J.M., 2002. The role of arginine vasotocin in teleost fish osmoregulation. In: Hazon, N., Flik, G. (Eds.), Osmoregulation and Drinking in Vertebrates. BIOS Scientific Publishers, Ltd, Oxford, pp. 83-95.

Warne, J.M., Bond, H., Weybourne, E., Sahajpal, V., Lu, W., Balment, R.J., 2005. Altered plasma and pituitary arginine vasotocin and hypothalamic provasotocin expression in flounder (Platichthys flesus) following hypertonic challenge and distribution of vasotocin receptors within the kidney. Gen. Comp. Endocrinol. $144,240-247$.

Zar, J.H., 1996. Biostatistical Analysis, 3rd ed. Prentice Hall, NJ. 